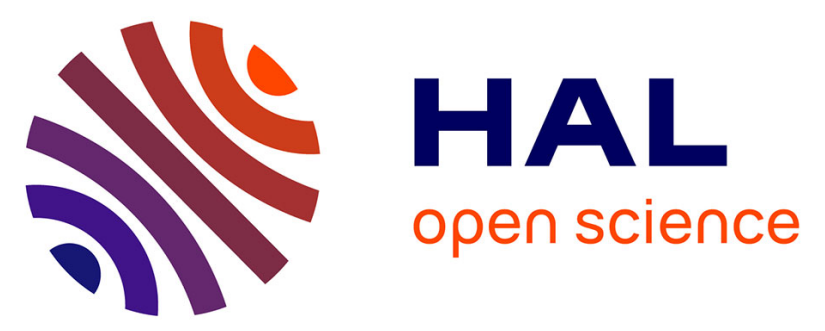

\title{
Unraveling the Environment Influence in Bistable Spin-Crossover Particles Using Magnetometric and Calorimetric First-Order Reverse Curves
}

Radu Tanasa, Cristian Enachescu, Jérôme Laisney, Denis Morineau, Alexandru Stancu, Marie-Laure Boillot

\section{To cite this version:}

Radu Tanasa, Cristian Enachescu, Jérôme Laisney, Denis Morineau, Alexandru Stancu, et al.. Unraveling the Environment Influence in Bistable Spin-Crossover Particles Using Magnetometric and Calorimetric First-Order Reverse Curves. Journal of Physical Chemistry C, 2019, 123 (15), pp.1012010129. 10.1021/acs.jpcc.9b00768 . hal-02143863

HAL Id: hal-02143863

https://hal-univ-rennes1.archives-ouvertes.fr/hal-02143863

Submitted on 29 May 2019

HAL is a multi-disciplinary open access archive for the deposit and dissemination of scientific research documents, whether they are published or not. The documents may come from teaching and research institutions in France or abroad, or from public or private research centers.
L'archive ouverte pluridisciplinaire HAL, est destinée au dépôt et à la diffusion de documents scientifiques de niveau recherche, publiés ou non, émanant des établissements d'enseignement et de recherche français ou étrangers, des laboratoires publics ou privés. 


\section{Unravelling The Environment Influence In Bistable}

\section{Spin Crossover Particles Using Magnetometric And}

\section{Calorimetric First Order Reverse Curves}

Radu Tanasa ${ }^{1}$, Cristian Enachescu ${ }^{1 *}$, Jérôme Laisney² ${ }^{\ddagger}$, Denis Morineau ${ }^{* *}$, Alexandru

Stancu ${ }^{1}$, Marie-Laure Boillot ${ }^{*}$

${ }^{1}$ Faculty of Physics, "Alexandru loan Cuza" University, 700506, lasi, Romania;

${ }^{2}$ Institut de Chimie Moléculaire et des Matériaux d'Orsay, Univ. Paris-Sud, Université

Paris-Saclay, CNRS, 91405 Orsay, France;

${ }^{3}$ Institut de Physique de Rennes, CNRS, Université de Rennes 1, UMR 6251, 35042

Rennes France;

$\ddagger$ Present address, Department of Plant and Soil Sciences, University of Kentucky,

Lexington, Kentucky, 40546, USA. 
*corresponding authors: cristian.enachescu@uaic.ro , marie-laure.boillot@u-psud.fr,

denis.morineau@univ-rennes1.fr

\begin{abstract}
First-order reversal curves (FORC) method is used here to analyze the unexpected change of memory characteristic of spin-crossover microparticles embedded in glassforming or semi-crystalline matrices, reflected in the larger hysteresis loop compared to the bulk. The huge reversibility shown by the reversal curves was attributed to an effect of matrix, implying a variable external pressure and a cut off - switch on mechanism of particle-matrix interactions. The FORC analysis indicates that heating and cooling processes in the case of matrix-embedded spin-crossover systems are driven by different mechanisms. In complement of standard magnetometry measurements, a calorimetry method, which demands an alternative method to extract FORC distributions, is
\end{abstract}


introduced for tracking the signature of the composite transformation, to understand and to control the role of embedding matrices.

\section{INTRODUCTION}

First-order reversal curves (FORC) method became recently a powerful tool for the characterization of hysteretic behavior in a broad range of materials, starting with magnetic materials ${ }^{1}$ and continuing with ferroelectric ${ }^{2}$ or geological samples ${ }^{3}$. For more than a decade, FORC method has been applied for understanding the properties of spin-crossover compounds ${ }^{4-7}$ as well. Spin-crossover (SC) compounds ${ }^{8-9}$ are inorganic molecular compounds, having a $\mathrm{d}^{4}-\mathrm{d}^{7}$ transition metal as central ion and situated in an octahedral ligand field. Due to classical thermodynamic reasons ${ }^{10}$, they can switch between two states, a high spin (HS) state - stable at high temperature and a low spin (LS) state, stable at lower temperature. The two states have different magnetic, optical, mechanical and volume properties making them suitable for applications. ${ }^{11-13}$ In the case of strong elastic interactions between spin-crossover units, the transition is 
accompanied by a thermal hysteresis loop. Though different as origin, the spincrossover thermal hysteresis presents some common features with the hysteresis of magnetic materials, which allowed their study using methods initially developed for ferromagnetism, such as the theoretical Preisach model ${ }^{14}$ which is the starting point of the experimental FORC technique ${ }^{4-5}$. One of these common features is the existence of spin-like domains, which has been proven for spin-crossover complexes in X-Ray Diffraction ${ }^{15}$ and Raman spectroscopy ${ }^{16}$ or optical microscopy ${ }^{17-18}$ experiments. Initial studies using the FORC method on spin-crossover complexes targeted the thermal hysteresis and they successfully described the spin-like domain properties in terms of physical parameters, such as the coercivity (intra- and inter-domain interactions) or bias (energy gap) ${ }^{5}$. Further analysis implied specific cases of kinetic light-induced thermal hysteresis ${ }^{6}$, systems with dopants ${ }^{19}$ or pressure hysteresis ${ }^{7}$, while a method to disentangle between kinetic and static components has been proposed as well. ${ }^{20}$ The main advantage of the FORC method is that it can be applied directly to experimental data like a characterization tool. 
The behavior of spin-crossover nano- and microparticles showed several differences compared to bulk compounds. Thus, spin-crossover nanoparticles thermal transition is more gradual, shifted towards lower temperature and sometimes incomplete, while the hysteresis loop has a smaller width, vanishes ${ }^{21}$ or even may reappear ${ }^{22-23}$ in case of a few nanometer size objects. Thus, FORC method was more difficult to apply and the number of studies remains still quite low. Still, the study of nanoparticles present some interesting features, for instance an important reversible component in the hysteretic behavior ${ }^{24}$, that could be assigned to an anhysteretic effect associated to over-critical size particles as in the case of polycrystalline samples.

Spin crossover nano- or microparticles were generally used as coated with stabilizers or dispersed in various media (surfactants, polymers, glass-forming matrices). The presence of such environment dramatically changes the overall properties of the nanoparticles system. ${ }^{23,} 25$ This initial observation triggered a number of both experimental ${ }^{26}$ and theoretical studies ${ }^{27-29}$, to figure out the effect of matrix/particle interactions. Moreover an unexpected widening of hysteresis loop have been detected 
in the case of microparticles embedded in various matrices, which was described as an effect of SC particles-matrix interactions. ${ }^{30}$ Experimental reversal curves showed no evidence for a cooperative process but a huge and surprising reversibility, explained as a cut-off / switch on of interactions, determined by the spin dependent particle volume and by the state of the surrounding matrix. ${ }^{31-32}$

Therefore, there is a need for more advanced experimental techniques to probe efficiently the changes in the switch behavior of the particles while interacting with the matrix. The FORC technique appears to be the most appropriate, as it is a powerful sensitive detector of intra- and inter-particles interactions changes. ${ }^{5}$

Here we use the FORC method to perform an in-depth study of hysteretic behavior of spin crossover Fe(II) microparticles dispersed in matrices, focusing on the notable deviations from the bulk materials. In addition to standard magnetometry technique showing the unexpected strong effects of matrix/particle interactions, we introduce here a complementary experimental technique based on calorimetric measurements. This technique enables to probe the change of state of both particles and matrix separately 
and therefore to better disentangle the behavior inherent to the embedding matrices and that of the spin-crossover microparticles. The paper is organized as follows: first we present magnetic and calorimetric studies of the thermal transition of spin-crossover microparticles embedded in glass-forming (or semi-crystalline) matrices - nujol, eicosan and glycerol-, then we present FORCs and FORC distributions in both magnetometric and calorimetric measurements. Methods and results are then discussed.

\section{EXPERIMENTAL SECTION}

a) Magnetic study of the thermal transition vs. the matrix nature

Microparticles of $\mathrm{Fe}(\text { phen })_{2}(\mathrm{NCS})_{2}$ have been synthesized according to a procedure described in Ref. ${ }^{33}$ Different characterizations including TEM, IR, Magnetic and XRD measurements confirmed the formation of pure crystalline $1.6(0.4) \times 1.6(0.4) \times 0.35(0.15)$ $\mu \mathrm{m}^{3}$ particles of the spin-transition compound (see SI for TEM images and powder XRay diagrams). The powder was then dispersed ${ }^{30}$ in eicosan, nujol or glycerol with a percentage of $2 \%$ (magnetism), $49 \%$ (or $4 \%$, calorimetry) spin active compound with respect to the dispersant. The solidification of eicosan leads to semi-crystalline domains 
at $T_{m}=310 \mathrm{~K}$ as proved by $\mathrm{X}$-ray diffraction. Nujol, a glass-forming oil $\left(T_{g}=200 \mathrm{~K}\right)$, shows a partial recrystallization between 205 and $270 \mathrm{~K}^{34}$, while the glass-transition temperature of glycerol is $T_{g} \sim 185-192 K .{ }^{35}$ The magnetic data have been obtained using a SQUID magnetometer (Quantum Design) at a constant magnetic field (5000 Oe), providing a susceptibility signal used to infer the high-spin fraction (denoted here as $\left.n_{H S}\right)$, which is the ratio of molecules in the HS state over the total number of molecules. The temperature sweeping rate was $0.3 \mathrm{~K} \cdot \mathrm{min}^{-1}$; several sweeping rates were considered and no dependence on this parameter was detected.

In Fig. 1, we present thermal transition curves for $\mathrm{Fe}(\text { phen })_{2}(\mathrm{NCS})_{2}$ as powder and as microparticles dispersed in glycerol (main figure), and eicosan and nujol (inset).

While the polycrystalline powder of $\mathrm{Fe}(\text { phen })_{2}(\mathrm{NCS})_{2}$ (see SI for a TEM image) shows a first-order spin-transition with a $2 \mathrm{~K}$ hysteresis loop centered around $176 \mathrm{~K}$, microcrystals of $\mathrm{Fe}(\text { phen })_{2}(\mathrm{NCS})_{2}$ dispersed in the selected matrices present a wider hysteresis loop, with a progressive HS-to-LS transition curve shifted toward smaller temperatures values and a LS-to-HS transition curve closely following the one obtained 
with polycrystalline powder in absence of any dispersing medium. In addition, in the case of particles dispersed in glycerol, two different hysteresis loops can be obtained depending on the previous thermal treatment of the ensemble, respectively if the composite was heated up to 190 or $250 \mathrm{~K}$ after the first cooling down. In order to determine the exact nature of the phase formed by the glycerol matrix and to better understand the effect of the thermal treatment on the shape of the hysteresis loop, we have performed Differential Scanning Calorimetry (DSC) experiments, which shall be presented in the next section. 


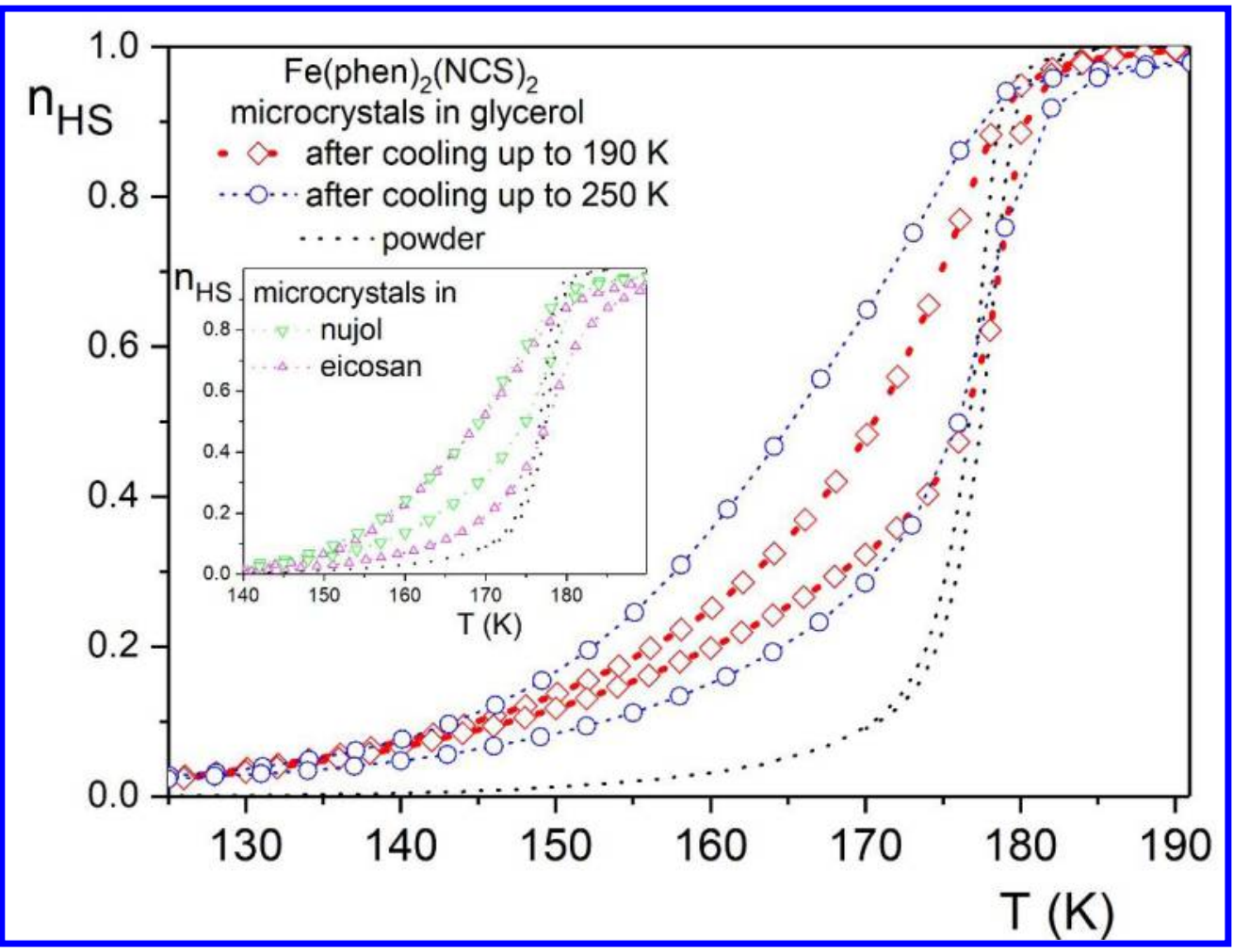

Figure 1 Major hysteresis loop (MHL) for $\mathrm{Fe}(\text { phen })_{2}(\mathrm{NCS})_{2}$ as polycrystalline powder

(dotted line) and as dispersions of crystalline microparticles in glycerol after a first

cooling down and heating up to 190 or $250 \mathrm{~K}$ (main figure) and as dispersions of

crystalline microparticles in nujol and eicosan after a first cooling down and heating up

to $190 \mathrm{~K}$ (inset). All measurements have been performed with a temperature sweeping

rate of $0.3 \mathrm{~K} \cdot \mathrm{min}^{-1}$.

b) Calorimetric study of the thermal transition 
Besides magnetic measurements, calorimetric measurements were intensively used to quantitatively evaluate the spin-crossover features ${ }^{36-39}$. Even the idea of spin-like domains mentioned above was initially formulated in the pioneering years of spincrossover phenomenon studies by Sorai and Seki while looking at the heat anomaly during first-order spin transition. ${ }^{40}$ This kind of measurement was used to determine relevant thermodynamical parameters, such as the enthalpy or the entropy changes accompanying the thermal transition. We briefly acknowledge that DSC measures the heat flow associated to the speed of progress of the spin transition, rather than the instantaneous fraction of transformed spins measured by magnetometric methods. It is sensitive to the phase transformations of both the microparticules (spin transition) and the embedding matrix (crystallization, melting, glass transition). This is obviously not the case for magnetometry and reflectometry measurements of spin-crossover compounds.

7 Therefore, DSC method is especially suited to study composite systems. Applying various thermal cycling techniques and more elaborate thermal treatments, one can prepare the matrix in well-defined state (liquid, solid, glass) and assess its impact on the microparticles spin-transition. 
The calorimetric measurements were performed on a TA Instrument Q20 DSC

equipped with a liquid-nitrogen cooling system. Three different samples were prepared and loaded in sealed aluminum pans: pure glycerol $(m=6.37 \mathrm{mg})$, free

$\mathrm{Fe}(\text { phen })_{2}(\mathrm{NCS})_{2}$ microparticles $(m=3.3 \mathrm{mg})$-both considered as reference systemsand a composite material formed by mixing $\mathrm{Fe}(\text { phen })_{2}(\mathrm{NCS})_{2}$ microparticles $(m=20.8$ $\mathrm{mg}$ ) with glycerol $(m=21.5 \mathrm{mg})$. The high mass ratio that was chosen for calibration reasons also allowed us to check the preservation of the experimental observations corresponding to 4 wt. \%. By convention, the thermograms are presented with the endothermic heat flow up. The heat flow was normalized with respect to the mass of $\mathrm{Fe}(\text { phen })_{2}(\mathrm{NCS})_{2}$ for both the free microparticles and the microparticles embedded in glycerol (so here equivalent to the mass of glycerol), while for pure glycerol, it was normalized to the mass of glycerol. Two different scanning rates were applied (10 $\mathrm{K} \cdot \mathrm{min}^{-1}$ and $0.5 \mathrm{~K} \cdot \mathrm{min}^{-1}$ ) as specified in the text.

In Fig. 2, we present the thermograms of these three systems acquired during heating at a constant rate $\left(10 \mathrm{~K} \cdot \mathrm{min}^{-1}\right)$ from 110 to $270 \mathrm{~K}$ after an initial cooling down from 273 
to $110 \mathrm{~K}$ at the same rate (not shown). For ensuring a better signal over noise response, we used here a percentage of $49 \%$ of powder of microparticles with respect to glycerol after checking the qualitative reproducibility of the phenomenon under investigation (49-4\% percentage). The thermogram of glycerol exhibits a jump of the heat capacity $\left(\Delta C_{\mathrm{p}}=0.85 \mathrm{~J} \cdot \mathrm{g}^{-1} \cdot \mathrm{K}^{-1}\right)$ at the glass temperature $T_{\mathrm{g}}=194 \mathrm{~K}\left(T_{\text {onset }}=192.3\right.$ $\mathrm{K})$, immediately followed by a small overshoot (see arrow), which is associated to enthalpic relaxation effects around Tg. Glycerol is a prototypical glass-forming system, and the crystallization could be easily avoided under these thermal conditions, as shown in Fig. 3. The thermal behavior and the measured values are in agreement with the literature for pure glycerol. ${ }^{41}$

The thermogram of free $\mathrm{Fe}(\text { phen })_{2}(\mathrm{NCS})_{2}$ microparticles exhibits a prominent endothermic peak (see arrow) $\left(T_{\max }=180.5 \mathrm{~K}, \Delta \mathrm{H}=11 \mathrm{~J} \cdot \mathrm{g}^{-1}=5.9 \mathrm{~kJ} \cdot \mathrm{mol}^{-1}\right)$ that corresponds to the LS-HS transition. During cooling, a very similar exothermic peak was observed at a nearby position, giving $T_{1 / 2}=178.5 \mathrm{~K}$ for the temperature of the center of the hysteresis loop. This is in agreement with the first-order and highly cooperative 
character of spin-transition discussed in the previous part concerning the magnetic property. The measured $\Delta \mathrm{H}$ and $\mathrm{T}_{1 / 2}$ parameters are fully consistent with those reported in the literature in case of the structurally characterized $\mathrm{Fe}(\text { phen })_{2}(\mathrm{NCS})_{2}$ materials in the so-called form II. ${ }^{42}$

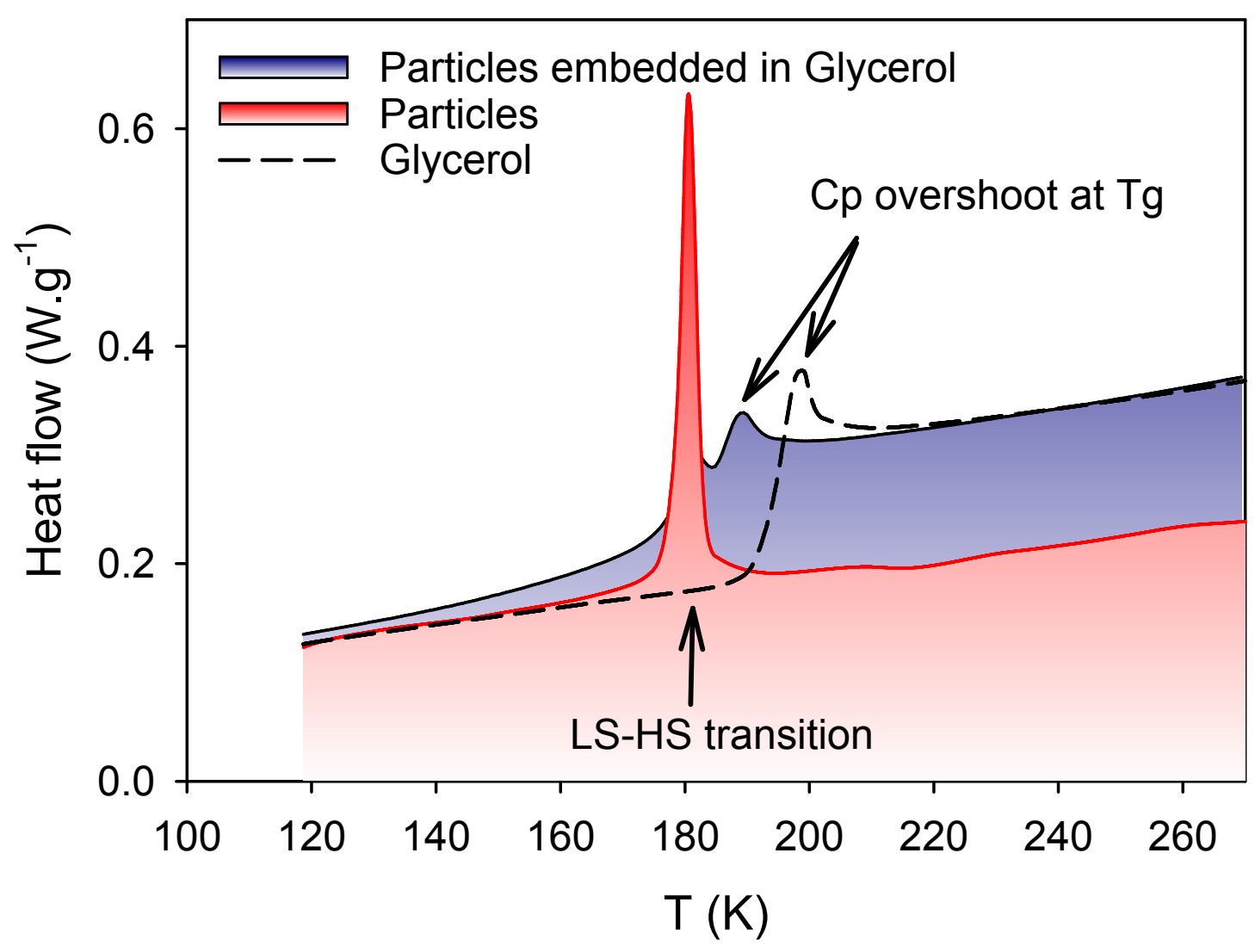


Figure 2 DSC thermograms recorded on heating after a first cooling down from 273 to $110 \mathrm{~K}$, with a temperature scanning rate of $10 \mathrm{~K} \cdot \mathrm{min}^{-1}$ for pure glycerol (dashed line), free $\mathrm{Fe}(\text { phen })_{2}(\mathrm{NCS})_{2}$ microparticles (red shaded) and $\mathrm{Fe}(\text { phen })_{2}(\mathrm{NCS})_{2}$ microparticles embedded in glycerol (blue line).

Next we discuss the thermogram of the $\mathrm{Fe}(\text { phen })_{2}(\mathrm{NCS})_{2}$ microparticles embedded in glycerol (blue shaded curve in Fig. 2). It presents a jump of the heat capacity that is actually a signature of the glass-to-liquid transition of the glycerol matrix. The glass transition temperature is slightly shifted towards lower temperature with respect to the pure glycerol, as indicated by the bump around $190 \mathrm{~K}$ instead of $198 \mathrm{~K}$, which corresponds to the overshoot of heat flux when crossing the glass-to-liquid transition. It indicates that the particles may have a small plasticizing ${ }^{43}$ influence on the dynamics of supercooled glycerol - the matrix itself has not only a complex behavior with an intrinsic hysteresis of mechanical origin, but also it is influenced by the size and density of spincrossover microparticles. More interestingly, this overshoot is preceded by a distinct endothermic peak ( $\left.T_{\max }=181 \mathrm{~K}\right)$, indicating the LS-HS transition of the dispersed 
microparticles. Despite a comparable position of the maximum peak, the transition of the $\mathrm{Fe}(\text { phen })_{2}(\mathrm{NCS})_{2}$ microparticles embedded in glycerol occurs much more gradually than for the free particles, feature which corresponds to magnetometry data. A broadening of the peak is observed and its low temperature side spreads out down to about $130 \mathrm{~K}$. It illustrates the progressive character of the spin transition of embedded particles - in other words the embedding destroys the cooperativity. So from these DSC measurements, we can be infer that the matrix and the SC particles are strongly coupled.

In the following, we shall explain the differences in thermal transition observed for glycerol environment after heating up to 190 or $250 \mathrm{~K}$. The different states of glycerol are sketched in Fig. 3, where the enthalpy is plotted over the temperature. While glycerol is solely liquid above the melting point $\left(T_{m}=291 \mathrm{~K}\right)$, it can exist in different forms at lower temperature. Below $T_{m}$, the equilibrium phase is crystalline, but glycerol can be usually supercooled in its metastable liquid state. On further cooling, the 
viscosity of the supercooled liquid is too high to fulfill equilibrium, so that it is eventually stuck into an out-of-equilibrium amorphous solid (glass transition $T_{g}=192 \mathrm{~K}$ ).

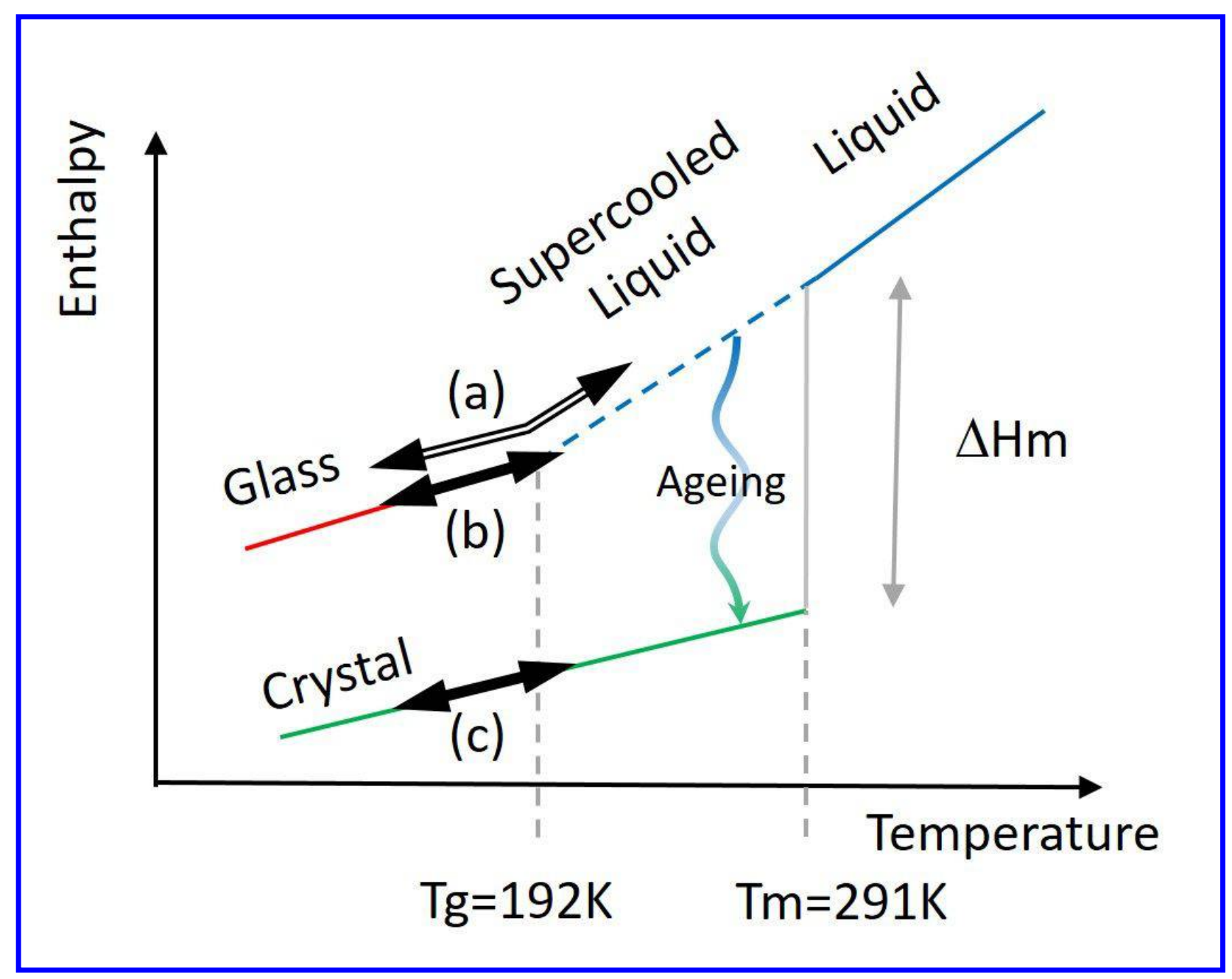

Figure 3 Schematic representation of glycerol stable and metastable phases. The thermal treatments are shown by arrows: (a) cycling in the glassy and liquid phases in 


\author{
the range 100-250 K, (b) cycling in glassy phase 100-190 K, and (c) cycling in the \\ crystal $100-190 \mathrm{~K} .\left(\right.$ adapted from ${ }^{44}$ )
}

In Fig. 4, we present the hysteresis loops recorded by DSC for two different cycling

conditions. The sample was firstly cooled down from 250 to $100 \mathrm{~K}$ (dashed line, noted

(a) in Fig. 3) and later cycled between 100 and $190 \mathrm{~K}$ (solid lines, noted (b) in Fig. 3). A

temperature rate of $0.5 \mathrm{~K} \cdot \mathrm{min}^{-1}$ was applied to facilitate comparison with the magnetic

measurements percentage. The first cooling branch shows sharp lines (spikes) that

dampen and disappear in the subsequent thermograms as long as the system is cycled

in the range $100-190 \mathrm{~K}$, but they appear again during the first cooling if the system is

heated above $250 \mathrm{~K}$. If one excepts these spikes, weak exothermic signals are visible

when comparing the two thermal cycles. A first signal can be detected around $170 \mathrm{~K}$

whatever the cycle, while a second one (magnified in S.I.) only appears in the range

$140-150 \mathrm{~K}$ after a sample first cooling from $273 \mathrm{~K}$. This small difference is systematic

and really significant as confirmed when zooming in and comparing different cycles (see

S.I.). In contrast, the heating branches cycled in the range $100-250 \mathrm{~K}$ and $100-190 \mathrm{~K}$ 
are always superimposed. They do not show any apparent dependence on the thermal history of the system.

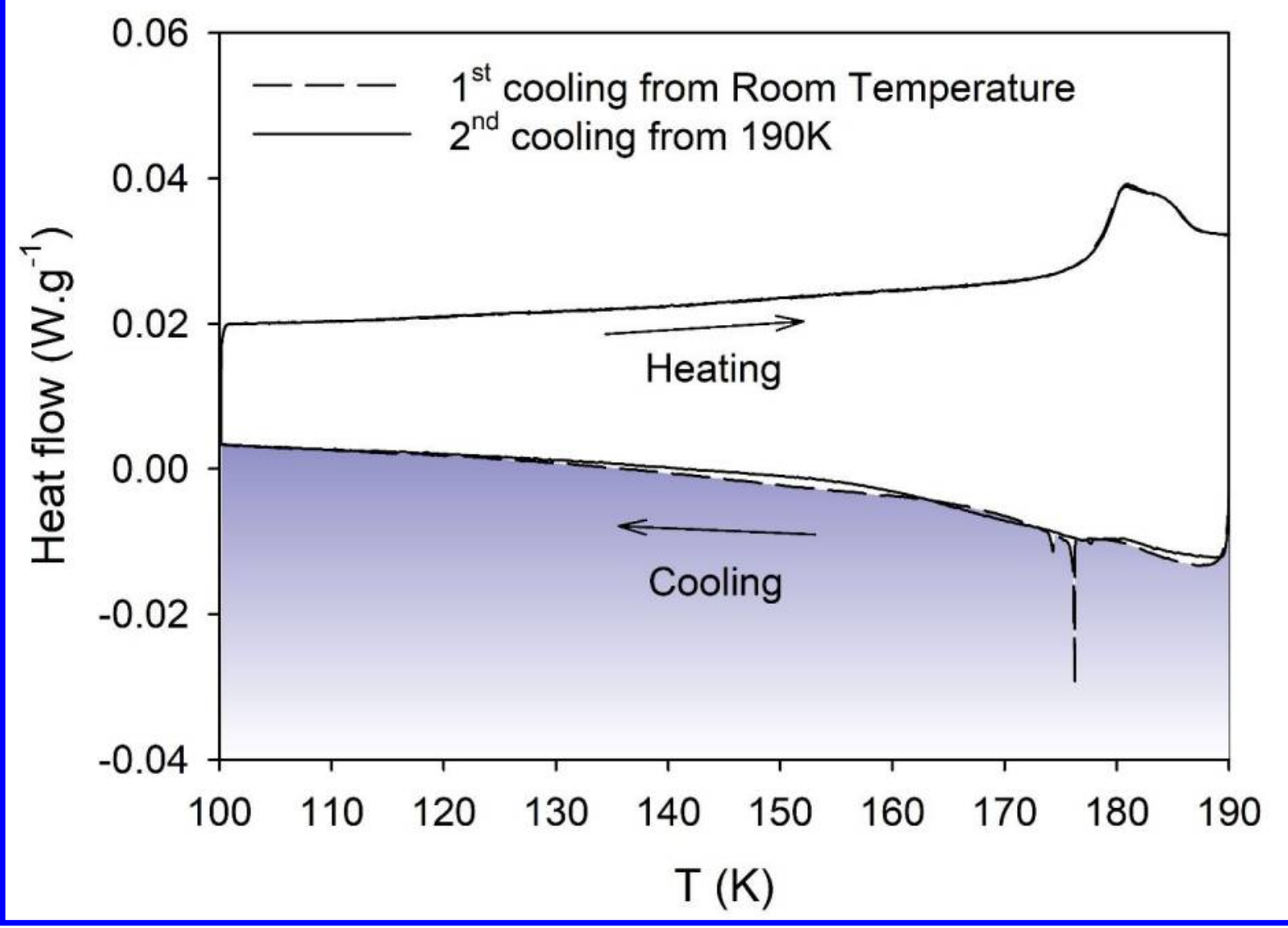

Figure 4 DSC thermograms of $\mathrm{Fe}(\text { phen })_{2}(\mathrm{NCS})_{2}$ microparticles embedded in glycerol recorded with a temperature scanning rate of $0.5 \mathrm{~K} \cdot \mathrm{min}^{-1}$ and with different cycling conditions. The two lower curves correspond to the cooling branches: a first cooldown after having heated the system above $250 \mathrm{~K}$ (dashed line) and a subsequent cooldown 


\author{
after heating up to $190 \mathrm{~K}$ (solid line). The two upper curves correspond to the heating \\ branches (superimposed solid lines).
}

This behavior is in line with the magnetic measurements shown in Fig. 1, which also indicated a clear variation of the cooling branch depending on the value of the upper temperature. The origin of this behavior can be hypothesized from a recent DSC study on glass-forming molecular systems. ${ }^{45}$ Similar thermal spikes due to a discontinuity of the thermal contact arising from the motion of seals aluminium pans were observed during cooling of glassy materials. They were attributed to the formation of cracks in the glassy phase well below $\mathrm{T}_{\mathrm{g}}$. Cracks arise from the sudden mechanical release of stresses that develop during deep quenches. As such, they usually appear $50 \mathrm{~K}$ or more below the glass-transition temperature. In S.I. we exemplify the broad peak by focusing only on the cooling branch.

In the present study, the spikes appear only a few degrees below the glass transition of glycerol. Under these mild conditions of supercooling, the glycerol matrix unexpectedly developed a significant amount of residual mechanical stresses. We rather infer that 
during the first cooling, the large volume contraction of the particles associated to the spin transition could not be sustained by the embedding frozen amorphous solid. The spikes associated to some degree of cracking of the matrix, and thus new free volumes, is indicative of an irreversible change in the microparticles-matrix interactions which necessarily impacts the spin crossover process as previously proposed (cutting-off of elastic interactions). It also introduces extra environment distribution and possible residual stress. The influence of non-relaxed particle-matrix interactions could explain the higher depression of the HS-LS transition along the major hysteresis loop (MHL) cooling branch (see exothermic broad peak in the range $140-150 \mathrm{~K}$ for the very first curve starting from a thermally quenched glassy state). The initial state of the composite (giving rise to elastic interactions and mechanical stresses) is recovered when the matrix is allowed to relax in the non-viscous liquid phase at a temperature well above $T_{g}$ (approximately $250 \mathrm{~K}$ ). These observations support the concepts of cut off/switch on of particles-matrix interactions when cycling through the glass transition of matrices, which were introduced recently in a mean-field model. ${ }^{31}$ 


\section{c) FORC ANALYSIS OF THE THERMAL HYSTERESIS}

In order to in-depth analyze the particle-matrix interactions, we have measured firstorder reversal curves for microparticles embedded in glycerol, and for comparison purpose in eicosan and nujol. The FORCs are a specific class of minor hysteresis loops, for which the sweep of the input parameter, temperature here, is reversed once from one of the branches of the major hysteresis loop.

For a hysteretic cooperative spin transition, the warming/cooling types of FORC experiments should be distinguished, according to the sign of the thermal variations.

The measurements start at a sufficiently high/low temperature, such that the high/low temperature (HS/LS) domain structure is saturated. Then, temperature is lowered/raised until a given temperature $T_{R} / T_{R}{ }^{*}$, the reversal temperature, and afterwards raised/lowered till reaching full HS/LS structures, in the heating/cooling mode respectively, as illustrated in Fig. 5 for the spin-crossover compound $\left[\mathrm{Fe}_{0.6} \mathrm{Zn}_{0.4}(\mathrm{btr})_{2}(\mathrm{NCS})_{2}\right] \cdot \mathrm{H}_{2} \mathrm{O}$. Typically, the experiment is repeated for several values of $T_{R} / T_{R}{ }^{*}$, and $n_{H S}\left(T_{r}, T\right) / n_{H S}{ }^{*}\left(T_{r}{ }^{*}, T\right)$ values forms the FORC data ( $T$ being the 
temperature at which the $n_{H S}$ is measured for $T_{R},\left(T_{R}^{*}\right)$ reversal temperature in the cooling (heating ) branch). The possibility to generate various states within the major hysteresis loop has been previously explained by the existence of the spin-like domains, which behaves similar to a rectangular hysteresis loop, denoted as hysteron in the Preisach formalism ${ }^{46}$ (see inset of Fig. 5). The collection of the hysterons forms the socalled Preisach distribution that, in magnetism, offers the statistical distribution either of the switching fields or of the coercivities and the interactions fields of hysterons. ${ }^{5,14}$ Indeed, the width of the thermal hysteron represents the coercivity, related to intradomain cooperative interactions, while its shift relative to the average transition temperature depends on inter-domain interactions.

The FORC distribution is defined as the second mixed derivative of these curves:

$$
\begin{gathered}
\rho\left(T_{R}, T\right)=-\frac{\partial^{2} n_{H S}\left(T_{R}, T\right)}{\partial T_{R} \partial T} \text { and } \\
\rho\left(T_{R}^{*}, T^{*}\right)=+\frac{\partial^{2} n_{H S}\left(T_{R}^{*}, T^{*}\right)}{\partial T_{R}^{*} \partial T^{*}}
\end{gathered}
$$


for heating and cooling modes, respectively.

The distribution of the switching temperatures is statistically stable in the case of noninteracting domains, which makes the FORC distributions to be similar, to the so-called Preisach distributions ${ }^{47}$. Consequently, the FORC distributions in the cooling and heating modes are expected to be the same, as is the case for the pure powder of the spin crossover compound $\left[\mathrm{Fe}(\mathrm{btr})_{2}(\mathrm{NCS})_{2}\right] \cdot \mathrm{H}_{2} \mathrm{O}$, whose typical FORC distributions are indicated in Fig. 6. For an easier comparison, we have represented the heating distribution in the classical Preisach half plane (below $T_{R}=T$ axis) and we have translated the cooling distribution in the half-plane situated above the $T_{R}=T$ axis. We notice then that the warming and cooling mode distributions tend to exhibit the expected mirror symmetry with respect to the $T_{R}=T$ axis. This symmetry can be related to the existence of only intra-domain interactions (a domain can be understood here as an entire particle). 


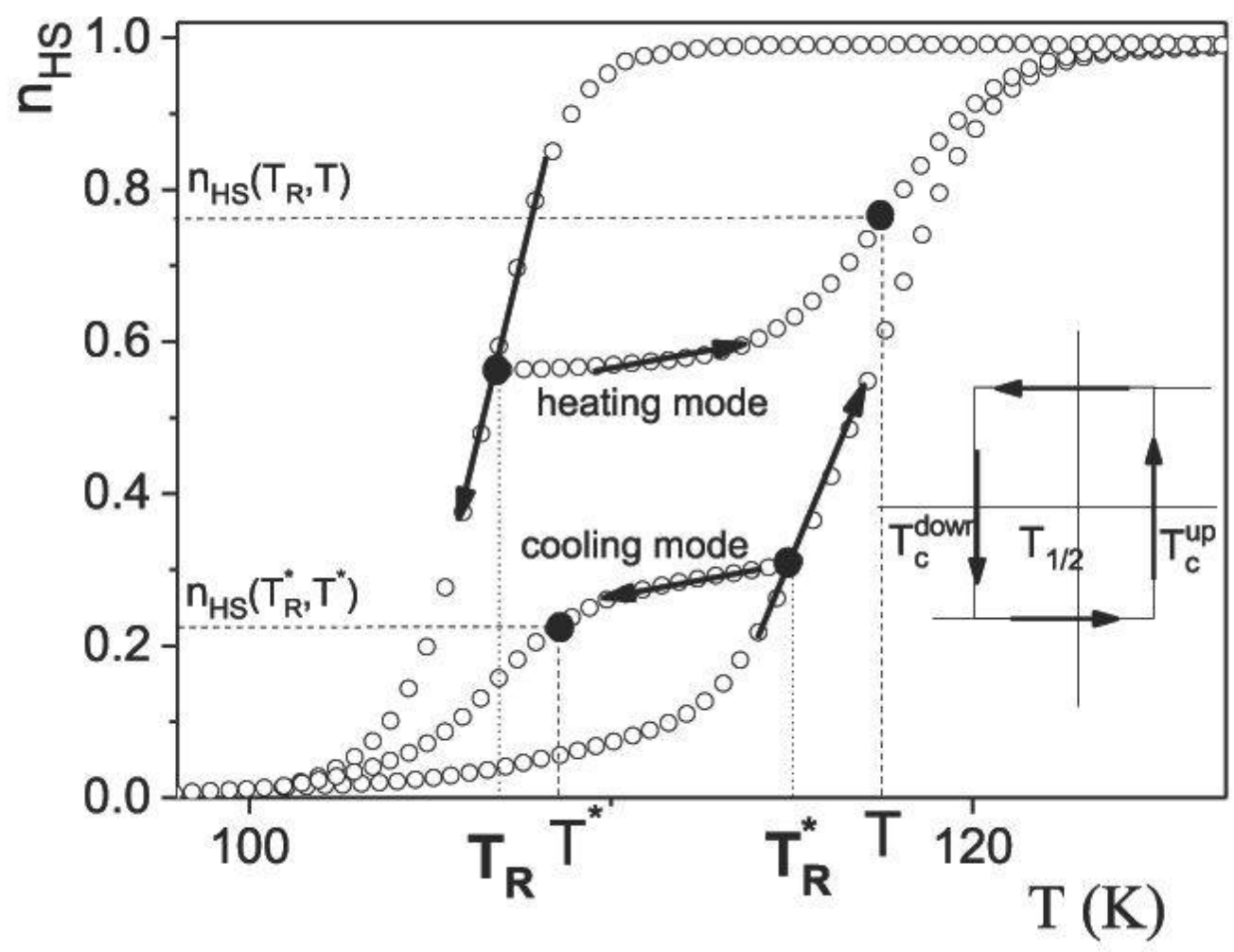

Figure 5 Examples of FORCs in warming and cooling modes; inset: typical hysteron

for cooperative interactions 


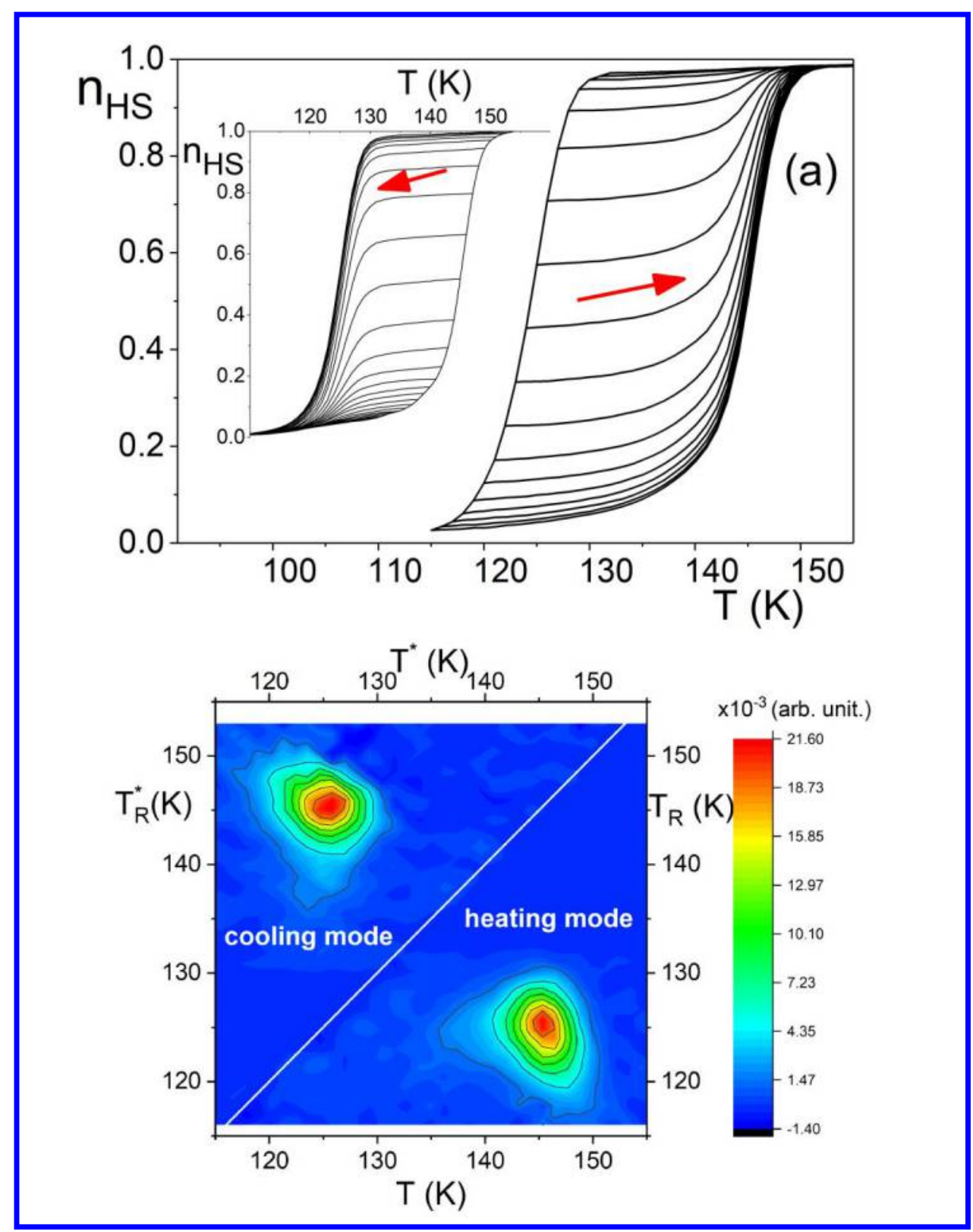

Figure 6 Typical FORCs in the case of powder spin-crossover compound

$\left[\mathrm{Fe}(\mathrm{btr})_{2}(\mathrm{NCS})_{2}\right] \cdot \mathrm{H}_{2} \mathrm{O}{ }^{5}$ (a) Main figure: heating mode, inset: cooling mode. (b) FORC distributions for heating (lower side) and cooling modes (upper side). 
In Figs. 7-10, we present experimental FORCs - in panels a) for FORCs in the heating mode and in the cooling mode (inset, corresponding to the ascending branch of the $\mathrm{MHL}$ )- and in panels b), calculated FORC distributions, as the second order mixed derivatives of $n_{H S}$ for both modes for $\mathrm{Fe}(\text { phen })_{2}(\mathrm{NCS})_{2}$ embedded in eicosan, nujol and glycerol respectively. In the case of glycerol, we distinguish in Figs. 9 and 10 the heating mode FORCs obtained with the saturation heating temperature of 190 or $250 \mathrm{~K}$ while for eicosan and nujol the saturation heating temperature in Fig. 7-8 is fixed at 190 K. In all situations, the FORCs exhibit the same peculiarities: they present a non-zero slope in the vicinity of the reversal temperature, which is a sign of an important reversible part. The latter that was not expected in case of pure sample ${ }^{5}$ could unfortunately not be probed, because of the small hysteresis width of $\mathrm{Fe}(\text { phen })_{2}(\mathrm{NCS})_{2}$ in the bulk form.

In addition, we notice that the slope of reversal curves depends on the individual reversal temperature. In the cooling mode, the FORCs are superimposable with the major hysteresis loop up to an unusually high value of $n_{H S}$, approaching 0.4 . For higher 
$n_{H S}$ values, they direct inside the hysteresis loop, but still remain far from a zero degree slope. In a similar manner, the curves in the heating mode are very close to the major hysteresis branch for a high value of $n_{H S}$, but start to enter into the hysteresis for smaller $n_{H S}$.

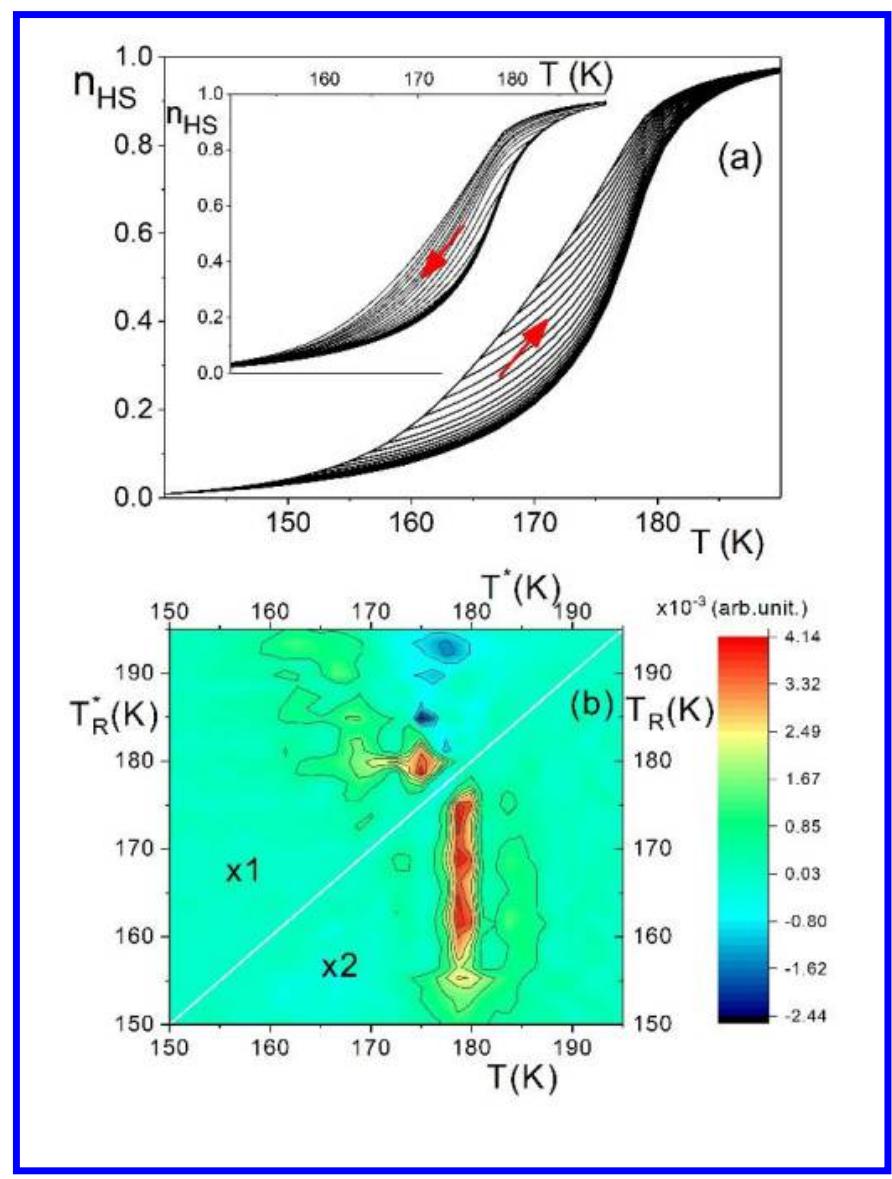


Figure 7 FORCs for Fe(phen $)_{2}(\mathrm{NCS})_{2}$ microparticles embedded in eicosan. (a) Main figure: heating mode $\left(T_{\mathrm{up}}=190 \mathrm{~K}\right)$, inset: cooling mode, $\left.T_{\text {down }}=140 \mathrm{~K}\right)$. (b) FORC distributions for heating (lower side, multiplied by 2) and cooling modes (upper side).

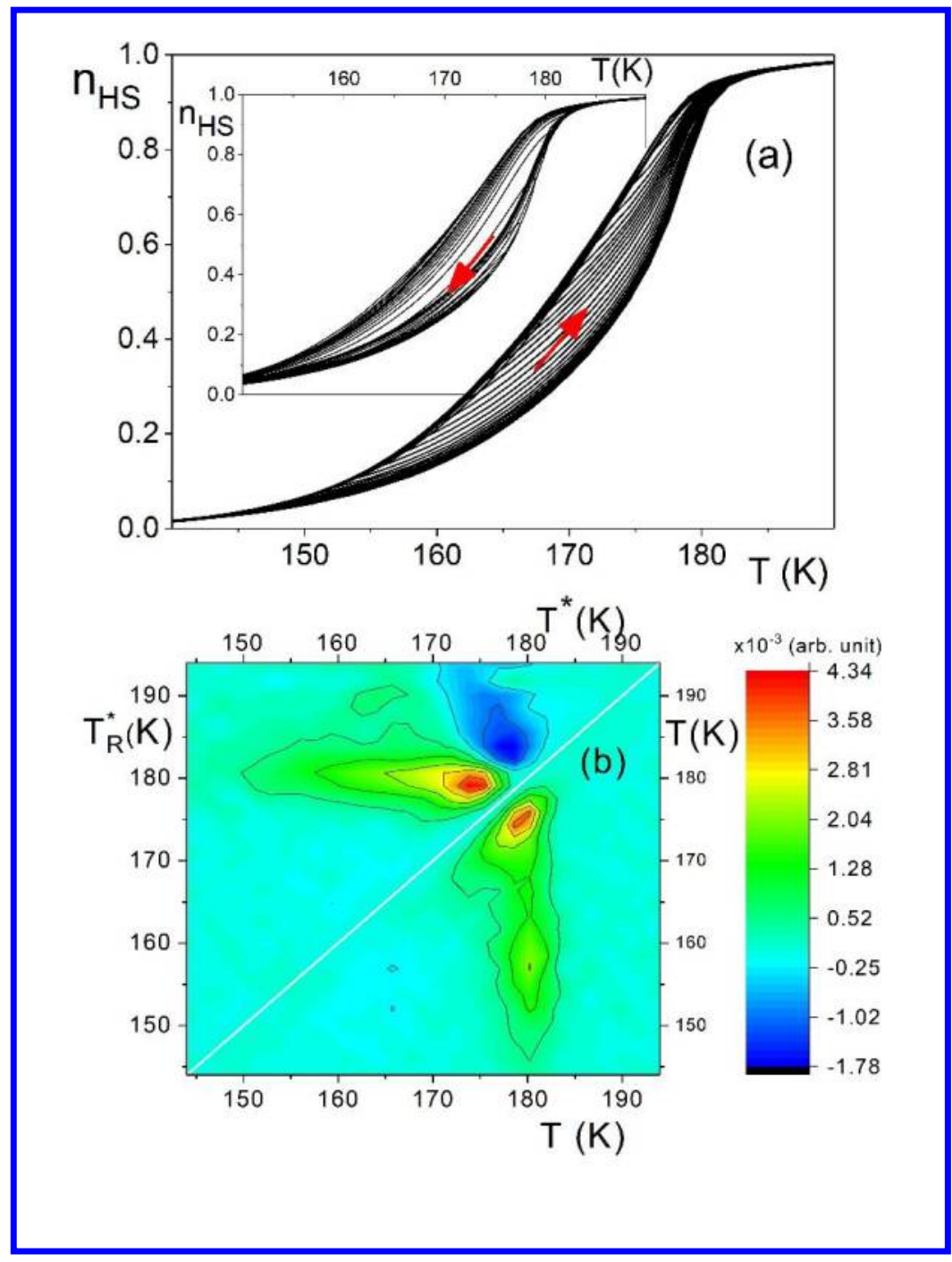


Figure 8 FORCs for $\mathrm{Fe}(\text { phen })_{2}(\mathrm{NCS})_{2}$ microparticles embedded in nujol. (a) Main

figure: heating mode $\left(T_{\text {up }}=190 \mathrm{~K}\right)$, inset: cooling mode $\left(T_{\text {down }}=140 \mathrm{~K}\right)$. (b) FORC distributions for heating (lower side) and cooling modes (upper side).

The analysis of the FORC distributions (Fig. $7 b-8 b-9 b-10 b)$ reveals other interesting features. As previously, we represent here the distribution in the two half planes of the Preisach plane, separated by the $T_{R}=T$ line, with the heating distribution below and the cooling distribution above this axis. The long shape of the main peaks is consistent with the progressive widening of the hysteresis loop and could be also connected with possible avalanche-type switchings. ${ }^{18,25}$

Regarding the different FORC distributions obtained for glycerol when cycling up to 190 and $250 \mathrm{~K}$ (Figs. 9, $10 \mathrm{~b}$ ), they indicate that the saturation should not be considered only as the situation of a fully HS/ LS structure, but also in connection with the environment characteristics (liquid or solid nature, phase stabilization). The differences observed in case of nujol and eicosan, two paraffinic species, are also instructive. Nujol 
becomes glassy while eicosan remains in a stable crystalline state. Accordingly, the changes in their FORC distributions can be assigned to the differences in the microparticles-matrix interactions as pointed above and thus to the elastic stability characteristics of the two solidified matrices. ${ }^{48}$

Another striking observation is the lack of the mirror symmetry in Figs. 7-10, in opposition to the model bulk case where FORC distributions obtained in the heating and cooling modes are rather similar (as shown in Fig. 6). This confirms first the effect of variable interactions between the microparticles and the matrix (as here they replace the classical interdomain interactions). Moreover it also shows that the processes at the two major hysteresis loop branches are different, which confirms the assumption previously made, when discussing only the major hysteresis cycle regarding a cut on /switch off mechanism, which implies the existence of elastic forces between the spin crossover microparticles and the surrounding matrix. Actually, in this case the physical representation of spin-like domains is different from the single-crystal picture, as every spin-crossover microparticle should be regarded as an independent single-domain 
particle. As stated in the introduction, the volume of individual spin-crossover molecules and consequently the whole microparticle volume diminish during the HS-to-LS transition. Then, the microparticle-matrix interactions vary when the HS-to-LS transition proceeds, due to the change of the spin-crossover microparticles volume, if the matrix is not elastic enough to follow this change. The variation of the matrix-microparticle interactions depends not only on the matrix elasticity and plasticity features, but also on the microparticles size: larger the size, the larger is the absolute variation during the transition and the variation of the distance between microparticle and matrix (see Fig. 11). This determines a variable distribution of interactions during HS-LS transition. Finally, if the microparticle volume after the HS-LS transition is too small, the distance between its surface and the matrix is so large that these interactions are suppressed and the microparticle does not feel anymore the influence of matrix. However, we expect that some small microparticles, whose absolute size variation is considerably reduced, still keep, at least partially, their connections to the matrix (see Fig. 11 for a schematic representation). We should notice that the inter-domain interaction distribution, as previously defined for spin-crossover compounds is replaced here with 
particle-matrix interaction. Therefore, while the HS-LS transition corresponds to a particle interacting with the surrounding matrix, the LS-HS transition is closer to that of an open boundary particle.

In the discussion above, we did not considered the presence of interactions between particles mediated by the matrix ${ }^{23,49}$, as in this case their possible effects are dampened by the particle-matrix interactions. As shown above, the hysteresis obtained for microparticles embedded in matrices is non-cooperative and therefore of a different nature than the cooperative hysteresis of the bulk. Consequently, it is not determined by the interactions mediated by the matrix (which should act similar to a bulk compound where the spin-active molecules interact each other by elastic strains. Here we find out new features elsewhere assigned to the formation of cracks of a glassy matrix (DSC signals) ${ }^{45}$ under the effect of internal shearing forces (solidification of pressuretransmitting oils) ${ }^{50}$ that are fully relevant with respect to this mechanism because of the change of volume of SC particles. 
Another interesting point is the presence of a negative region on the FORC distributions in the cooling mode FORCs, which can be noticed for all matrices.

Generally speaking, negative regions in FORCs distributions were attributed to the change in susceptibility variation between successive curves. Here the susceptibility is given by the number of microparticles multiplied by their size. According to discussions in previous paragraph, the larger microparticles are the first for which the interactions with the matrix are cut during HS-LS transitions. Consequently, in this case a change in susceptibility variation is possible, as a smaller number of large spin crossover microparticles can count more than a larger number of average size spin crossover microparticles. We have to strengthen that the origin of this negative distribution is different from the negative distributions observed for rate dependent light induced thermal hysteresis in spin crossover compounds ${ }^{6}$ or in the case of potential-driven hysteresis in model electrochemical systems ${ }^{51}$ where it is due to the evolution of the system toward the stable state, even after the direction of change of the control parameter has changed. 

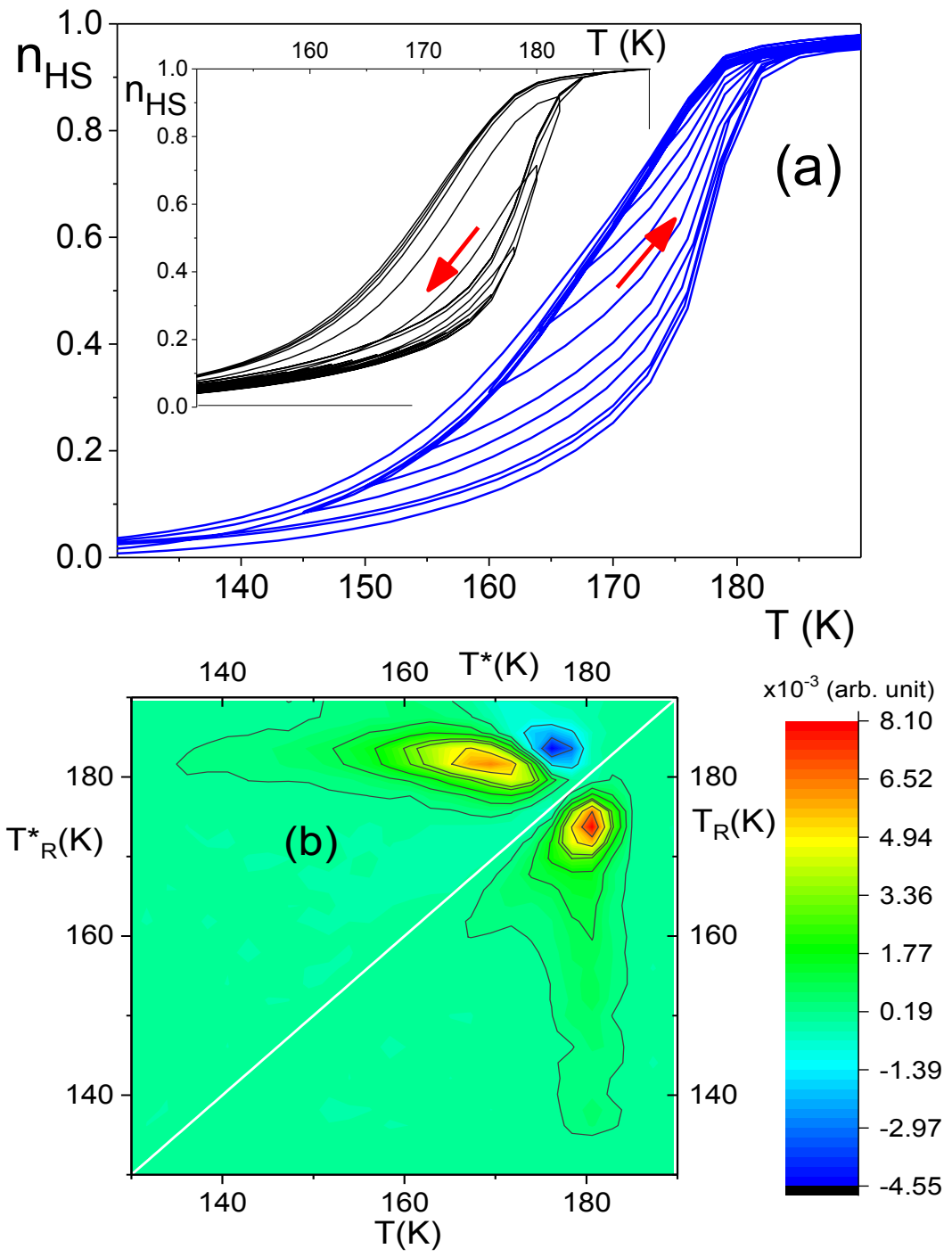

Figure 9 (a) FORCs for $\mathrm{Fe}(\text { phen })_{2}(\mathrm{NCS})_{2}$ microparticles embedded in glycerol for warming mode when cycling up to $250 \mathrm{~K}$, (main figure) and cooling modes (inset) (b) Corresponding FORC distributions. The temperature scan rate was $0.3 \mathrm{~K} \cdot \mathrm{min}^{-1}$. 

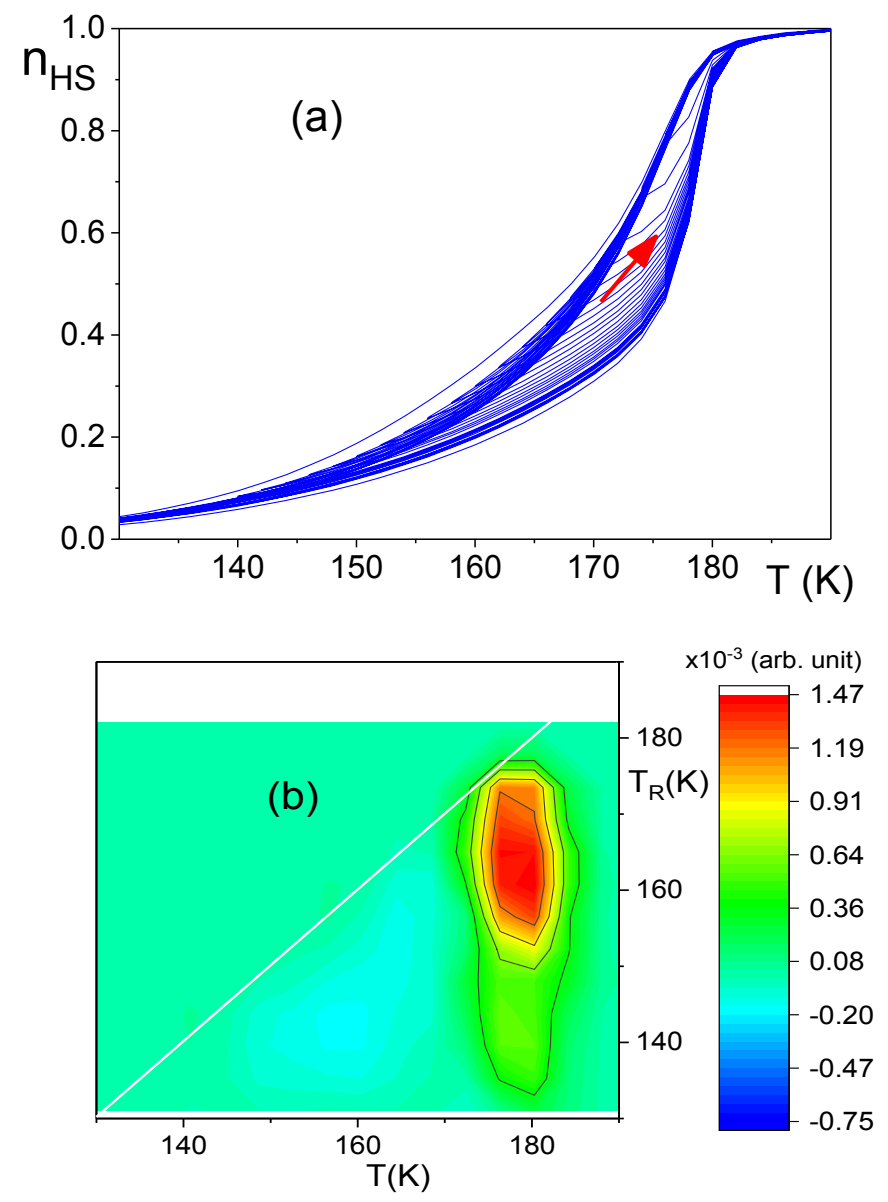

Figure 10 (a) FORCs for $\mathrm{Fe}(\text { phen })_{2}(\mathrm{NCS})_{2}$ microparticles embedded in glycerol for warming mode when cycling up to $190 \mathrm{~K}$ (main figure) (b) Corresponding FORC distributions. The temperature scan rate was $0.3 \mathrm{~K} \cdot \mathrm{min}^{-1}$.

We have to notice how the huge reversible component in the heating / cooling branch of the major hysteresis loop varies with the matrix preparation. The behavior in the case of $\mathrm{Fe}(\text { phen })_{2}(\mathrm{NCS})_{2}$ microparticles embedded in glycerol (Figs. 9, 10) is in part 
similar with that of microparticles embedded in other matrices, but show some peculiarities. The FORCs starting from the MHL cooling branch measured for microparticles embedded in glycerol change when the temperature is cycled up to 250 $\mathrm{K}$ or up to $190 \mathrm{~K}$. In the first case, the large reversible part in the cooling branch is similar to the case of nujol, while in the second case, the reversible part is noticeably smaller and the hysteresis loop slightly varies while cycling the temperature. According to the calorimetric study (section II.B), it can be observed that the thermal cycling of the composite up to $190 \mathrm{~K}$ results an irreversible loss of connectivity between particles and matrix (matrix cracking). It can be suggested that both the decrease of the hysteresis width shown in Fig. 4 and Fig. 9a. and the weaker FORC reversible component result from the cracking (release of stresses) of the composites. This hypothesis is also justified by the opposite trends observed when the temperature is cycled up to $250 \mathrm{~K}$, i.e. well above the glass-transition of the glycerol52 in conditions allowing the restoration of the particles-matrix interactions. 


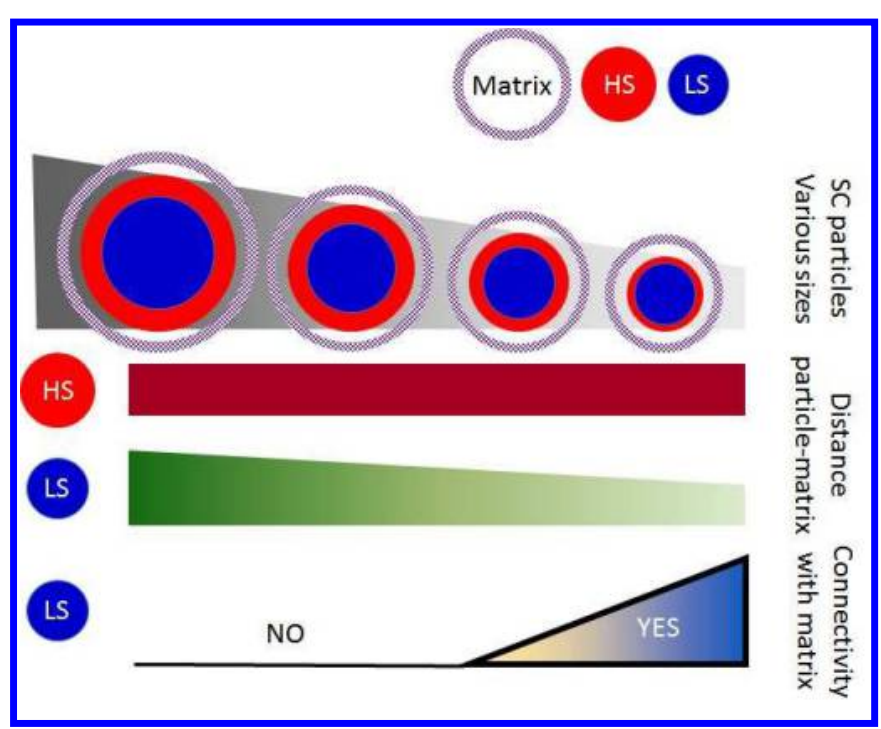

Figure 11 Schematic representation of particle-matrix interactions during HS-LS

transition

d) FORC APPROACH/ANALYSIS: THE CALORIMETRIC INPUT

To confirm these findings, we have performed the same measurements based on the calorimetric technique, which provides a unique complement to the magnetometric FORCs method.

Considering the relevance of calorimetric measurements in the study of composite systems, we measured DSC-like FORCs. Mimicking the magnetometric experiments protocols discussed previously, we acquired thermograms in the heating mode, starting 
from different lower temperatures ( $T_{R}$ in the range 100-190 K) to the same upper temperature $\left(T_{\text {up }}=190 \mathrm{~K}\right)$. Both heating and cooling rates were set to $0.5 \mathrm{~K} \cdot \mathrm{min}^{-1}$. In order to control the nature of the embedding matrix, two different thermal treatments were applied prior to the DSC-like FORCs experiments. In the first case, the sample was cooled down from 300 to $190 \mathrm{~K}$ and then cycled once between 100 and $190 \mathrm{~K}$, in order to prepare glycerol as a glassy matrix with relaxed elastic interactions (no residual spikes as shown in Fig. 4) with the $\mathrm{Fe}(\text { phen })_{2}(\mathrm{NCS})_{2}$ microparticles. The subsequent FORCs were measured for a glassy or very viscous liquid matrix (denoted as case (b) in Fig. 3). In a second case, the sample was cooled down to $100 \mathrm{~K}$ and heated up to 270 $\mathrm{K}$. This thermal treatment, which combines a deep quench in the glass and a thermalization in the slightly supercooled liquid promotes the nucleation and the growth of the crystalline phase. The subsequent FORCs were measured for a crystalline matrix (denoted as case (c) in Fig. 3). It can be noted here that the behavior observed upon the first cooling of the composite formed with the glassy or the crystalline matrix is qualitatively unchanged. 
The corresponding experimental FORCs measured while heating and that starts from the cooling branch are shown in Fig. 12. The heat flow in Fig. 12a cumulates the enthalpy LS-HS transition and the heat capacity jump of glass-liquid transition of glycerol, while in Fig. 12b it accounts only for the enthalpy of LS-HS transition, glycerol being crystallized.

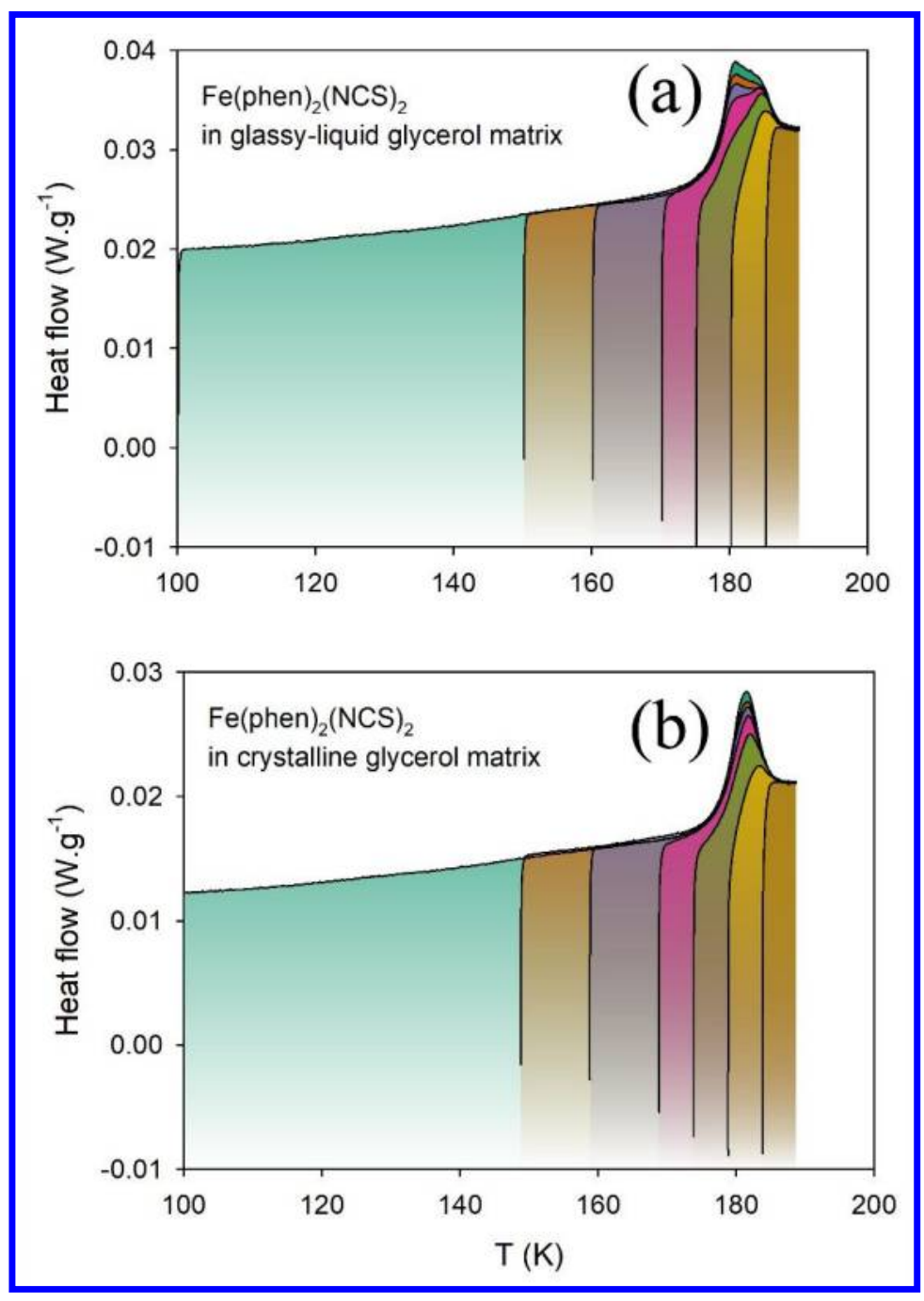


Figure 12 First Order Reversal Curves DSC thermograms in the heating mode for composites of $\mathrm{Fe}(\text { phen })_{2}(\mathrm{NCS})_{2}$ microparticles embedded in glassy (a) and crystalline (b) glycerol. Scanning rate: $0.5 \mathrm{~K} \cdot \mathrm{min}^{-1}$.

The recording of calorimetric FORCs as heat capacity profiles opened the possibility to represent FORC distributions for calorimetric data. However, there is an important difference compared to the standard method for obtaining FORC distribution: as the heat capacity already corresponds to the first derivative of the $n_{H S}$ with the temperature, only a single derivative is necessary in order to obtain the FORC distributions. The concept of using of a single derivative to get the FORC diagram was theoretically mentioned, however without practical implementation, more than a decade ago, in a study concerning the voltammetric current in electrochemical FORC method ${ }^{51}$. One has to strengthen that the specificity of this experiment is the quite large temperature step between two consecutive reversal temperatures, due to the necessity to measure all curves in the same conditions and to the time limitations of the experimental device; in the same time the temperature step for a given value of the reversal temperature 
should be small to obtain smooth curves (representing the first derivative of $n_{H S}$, as we have explained before). In Fig. 12, we present FORC distributions in the heating mode obtained using calorimetric data for $\mathrm{Fe}(\text { phen })_{2}(\mathrm{NCS})_{2}$ spin crossover microparticles embedded in glassy (when cooling down from $190 \mathrm{~K}$ ) and crystalline (when cooling down from $270 \mathrm{~K}$ ) glycerol compounds. Even not so preeminent, the maxima of the distributions are situated at the same value as obtained from the magnetometry curves. The high/sharp peaks along $\mathrm{T}_{\mathrm{R}}=\mathrm{T}$ line (which are here more clear than in magnetometric FORC discussed previously) are due to the reversible part of the curves. In the case of the crystalline matrix, a kink is visible for the distribution around $180 \mathrm{~K}$, sign of a different interaction between the spin-crossover particle and the matrix. A complete study of the peculiarities of the FORC technique obtained using the calorimetry experiment will be realized in a further study. 


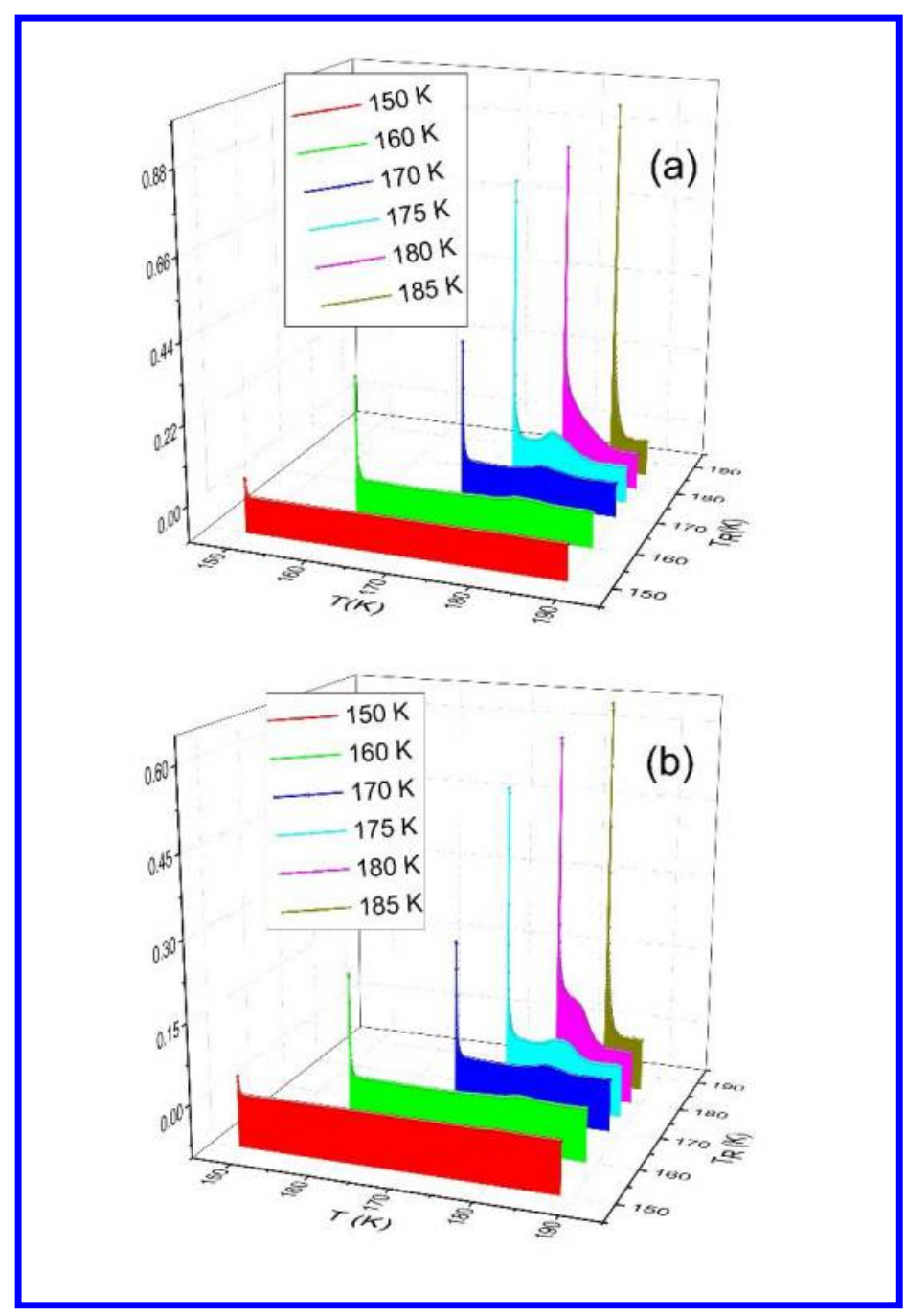

Figure 12 Calorimetric FORC distributions for compound embedded in glassy (a, up) and crystalline matrices ( $b$, down). Note the reversible component (the high peaks) and the irreversible ones.

\section{CONCLUSIONS}


In this paper, we have analyzed the influence of various glass-forming and semicrystalline matrices on the properties of embedded spin-crossover Fe(phen $)_{2}(\mathrm{NCS})_{2}$ microparticles, as reflected in the thermal transition loop based on FORC technique, applied both to magnetometry and calorimetry experiments. The hypothesis of variable interactions between spin-crossover particles and matrices has been confirmed by magnetometric FORCs. The hysteresis shown by spin-crossover microparticles embedded in matrices is not due to the cooperative elastic interactions between the SC sites inside the microparticles, but is a result of more or less active interactions with the matrix depending of its mechanical properties. It is similar with the hysteresis specific to heterostructures. This work clearly shows that an active matrix could be the path to follow for a controllable microparticle-switching paradigm. A complementary FORC method based on calorimetric data, which is essential when the particles actively interact with the environment, has been proposed, and the results have been corroborated with magnetometry data. An original treatment of calorimetric FORCs implying one single derivative has been proposed and should be developed in a future work. 
Points to be considered should refer to the matrix transformations with respect to the spin crossover and its combination with size reduction and to the investigation of the effects of light irradiation. The present study can be extended to phase transition in composite $^{52-53}$ and role of moistening in porous materials like silica or chitosan. ${ }^{54-56}$

\section{SUPPORTING INFORMATION}

TEM image and X-Ray diffractograms of $\mathrm{Fe}(\text { phen })_{2}(\mathrm{NCS})_{2}$ in the form of microcrystals. DSC thermograms of $\mathrm{Fe}(\text { phen })_{2}(\mathrm{NCS})_{2}$ microparticles.

\section{ACKNOWLEDGMENT}

The work was funded by the Romanian Ministry of Research and Innovation within

Program 1 - Development of the national RD system, Subprogram 1.22 - Institutional

Performance - RDI excellence funding projects, Contract no.34PFE/19.10.2018 and by

the CNRS, the French Ministry of Research. The collaboration between Romanian and

French teams has been supported by PHC Brancusi. DM acknowledges funding from

Rennes Metropole and from European FEDER Fund. 


\section{REFERENCES}

1. Pike, C. R.; Roberts, A. P.; Verosub, K. L., Characterizing Interactions in Fine Magnetic Particle Systems Using First Order Reversal Curves. J. Appl. Phys. 1999, 85, 6660.

2. Stancu, A.; Ricinschi, D.; Mitoseriu, L.; Postolache, P.; Okuyama, M., First-Order Reversal Curves Diagrams for the Characterization of Ferroelectric Switching. Appl Phys Lett 2003, 83, 3767-3769.

3. Pike, C. R.; Roberts, A. P.; Verosub, K. L., First-Order Reversal Curve Diagrams and Thermal Relaxation Effects in Magnetic Particles. Geophys. J. Int. 2001, 145, 721.

4. Enachescu, C.; Tanasa, R.; Stancu, A.; Codjovi, E.; Linares, J.; Varret, F., Forc Method Applied to the Thermal Hysteresis of Spin Transition Solids: First Approach of Static and Kinetic Properties. Physica B 2004, 343, 15-19.

5. Tanasa, R.; Enachescu, C.; Stancu, A.; Linares, J.; Codjovi, E.; Varret, F.; Haasnoot, J. G., First-Order Reversal Curve Analysis of Spin-Transition Thermal Hysteresis in Terms of Physical-Parameter Distributions and Their Correlations. Phys. Rev. B 2005, 71, 014431. 
6. Enachescu, C.; Tanasa, R.; Stancu, A.; Varret, F.; Linares, J.; Codjovi, E., FirstOrder Reversal Curves Analysis of Rate-Dependent Hysteresis: The Example of LightInduced Thermal Hysteresis in a Spin-Crossover Solid. Phys. Rev. B 2005, 72, 054413.

7. Rotaru, A.; Linares, J.; Varret, F.; Codjovi, E.; Slimani, A.; Tanasa, R.; Enachescu, C.; Stancu, A.; Haasnoot, J., Pressure Effect Investigated with First-Order ReversalCurve Method on the Spin-Transition Compounds $\left[\mathrm{Fe}_{\mathrm{x}} \mathrm{Zn}_{1-\mathrm{x}}(\mathrm{btr})_{2}(\mathrm{NCS})_{2}\right] \mathrm{H}_{2} \mathrm{O}(\mathrm{x}=0.6,1)$. Phys. Rev. B 2011, 83, 224107.

8. Halcrow, M. A., Spin-Crossover Materials - Properties and Applications. John Wiley \& Sons: Chichester, UK, 2013.

9. Gütlich, P.; Goodwin, A., Spin Crossover in Transition Metal Compounds Springer: Heidelberg, 2004; Vol. I-III.

10. Nicolazzi, W.; Bousseksou, A., Thermodynamical Aspects of the Spin Crossover Phenomenon. C. R. Chim. 2018, 21, 1060-1075.

11. Boukheddaden, K.; Ritti, M. H.; Bouchez, G.; Sy, M.; Dirtu, M. M.; Parlier, M.; Linares, J.; Garcia, Y., Quantitative Contact Pressure Sensor Based on Spin Crossover Mechanism for Civil Security Applications. J. Phys. Chem. C 2018, 122, 7597-7604. 
12. Létard, J. F.; Guionneau, P.; Goux-Capes, L., Towards Spin Crossover Applications. Top Curr Chem 2004, 235, 221-249.

13. Ohkoshi, S.; Imoto, K.; Tsunobuchi, Y.; Takano, S.; Tokoro, H., Light-Induced Spin-Crossover Magnet. Nat. Chem. 2011, 3, 564-569.

14. Enachescu, C.; Machado, H. C.; Menendez, N.; Codjovi, E.; Linares, J.; Varret, F.; Stancu, A., Static and Light Induced Hysteresis in Spin-Crossover Compounds:Experimental Data and Application of Preisach-Type Models. Physica B 2001, 306, 155.

15. Pillet, S.; Hubsch, J.; Lecomte, C., Single Crystal Diffraction Analysis of the Thermal Spin Conversion in $\left[\mathrm{Fe}(\mathrm{btr})_{2}(\mathrm{NCS})_{2}\right]\left(\mathrm{H}_{2} \mathrm{O}\right)$ : Evidence for Spin-Like Domain Formation. Eur. Phys. J. B 2004, 38, 541-552.

16. Molnár, G.; Bousseksou, A.; Zwick, A.; McGarvey, J. J., The Spin-Crossover Phenomenon in the Solid State: Do Domains Play a Role? A Micro-Raman Study. Chem . Phys. Lett. 2003, 367, 593-598.

17. Bonnet, S.; Molnar, G.; Sanchez-Costa, J.; Siegler, A. M.; Spek, A. L.; Bousseksou, A.; Fu, W. T.; Gamez, P.; Reedijk, J., Influence of Sample Preparation, 
Temperature, Light, and Pressure on the Two-Step Spin Crossover Mononuclear Compound [Fe(Bapbpy)(NCS) 2 ]. Chem. Mater. 2009, 1121-1136.

18. Sy, M.; Traiche, R.; Fourati, H.; Singh, Y.; Varret, F.; Boukheddaden, K., Spatiotemporal Investigations on Light-Driven High-Spin-Low-Spin Interface Dynamics in the Thermal Hysteresis Region of a Spin-Crossover Single Crystal. J. Phys. Chem. C 2018, 122, 20952-20962.

19. Tanasa, R.; Enachescu, C.; Stancu, A.; Varret, F.; Linares, J.; Codjovi, E., Study of Impurities Effect in Spin Crossover Compounds Using First Order Reversal Curves (FORC) Method. Polyhedron 2007, 26, 1820-1824.

20. Stan, R. M.; Gaina, R.; Enachescu, C.; Tanasa, R.; Stancu, A.; Bronisz, R., Kinetic Effects on Double Hysteresis in Spin Crossover Molecular Magnets Analyzed with First Order Reversal Curve Diagram Technique. J.. Appl. Phys. 2015, 117.

21. Volatron, F.; Catala, L.; Riviere, E.; Gloter, A.; Stephan, O.; Mallah, T., SpinCrossover Coordination Nanoparticles. Inorg. Chem. 2008, 47, 6584.

22. Félix, G.; Nicolazzi, W.; Salmon, L.; Molnár, G.; Perrier, M.; Maurin, G.; Larionova, J.; Long, J.; Guari, Y.; Bousseksou, A., Enhanced Cooperative Interactions at the 
Nanoscale in Spin-Crossover Materials with a First-Order Phase Transition. Phys. Rev.

Lett. 2013, 110, 235701.

23. Raza, Y., et al., Matrix-Dependent Cooperativity in Spin Crossover Fe(Pyrazine)Pt(Cn)4 Nanoparticles Chem. Commun. 2011, 47, 11501-11503.

24. Rotaru, A.; Varret, F.; Gindulescu, A.; Linarès, J.; Stancu, A.; Létard, J. F.; Forestier, T.; Etrillard, C., Size Effect in Spin-Crossover Systems Investigated by Forc Measurements, for Surfacted $\left[\mathrm{Fe}\left(\mathrm{NH}_{2}-\mathrm{Trz}\right)_{3}\right](\mathrm{Br})_{2} \cdot 3 \mathrm{H}_{2} \mathrm{O}$ Nanoparticles: Reversible Contributions and Critical Size. Eur. Phys. J. B 2011, 84, 439-449.

25. Stoleriu, L.; Chakraborty, P.; Hauser, A.; Stancu, A.; Enachescu, C., Thermal Hysteresis in Spin-Crossover Compounds Studied within the Mechanoelastic Model and Its Potential Application to Nanoparticles. Phys. Rev. B 2011, 84, 134102.

26. Mikolasek, M.; Felix, G.; Peng, H.; Rat, S.; Terki, F.; Chumakov, A. I.; Salmon, L.; Molnár, G.; Nicolazzi, W.; Bousseksou, A., Finite-Size Effects on the Lattice Dynamics in Spin Crossover Nanomaterials. I. Nuclear Inelastic Scattering Investigation. Phys Rev B 2017, 96, 035426. 
27. Felix, G.; Mikolasek, M.; Molnar, G.; Nicolazzi, W.; Bousseksou, A., Tuning the Spin Crossover in Nano-Objects: From Hollow to Core-Shell Particles. Chemi. Phys. Lett. 2014, 607, 10-14.

28. Oubouchou, H.; Singh, Y.; Boukheddaden, K., Magnetoelastic Modeling of CoreShell Spin-Crossover Nanocomposites. Phys. Rev. B 2018, 98.

29. Atitoaie, A.; Tanasa, R.; Stancu, A.; Enachescu, C., Study of Spin Crossover Nanoparticles Thermal Hysteresis Using FORC Diagrams on an Ising-Like Model. J. Magn. Magn. Mater. 2014, 368, 12-18.

30. Tissot, A.; Enachescu, C.; Boillot, M. L., Control of the Thermal Hysteresis of the Prototypal Spin-Transition $\mathrm{Fe}_{\mathrm{ii}}(\mathrm{Phen}) 2(\mathrm{Ncs}) 2$ Compound Via the Microcrystallites Environment: Experiments and Mechanoelastic Model J. Mater. Chem. 2012, 22, 2045120457.

31. Tanasa, R.; Laisney, J.; Stancu, A.; Boillot, M. L.; Enachescu, C., Hysteretic Behavior of Fe(Phen)(2)(Ncs)(2) Spin-Transition Microparticles Vs. The Environment: A Huge Reversible Component Resolved by First Order Reversal Curves. Appl. Phys. Lett. 2014, 104, 031909. 
32. Enachescu, C.; Tanasa, R.; Stancu, A.; Tissot, A.; Laisney, J.; Boillot, M. L., MatrixAssisted Relaxation in Fe(Phen) $)_{(2)}(\mathrm{NCS})_{(2)}$ Spin-Crossover Microparticles, Experimental and Theoretical Investigations. Appl Phys Lett 2016, 109.

33. Laisney, J.; Tissot, A.; Molnar, G.; Rechignat, L.; Rivière, E.; Brisset, F.; Bousseksou, A.; Boillot, M. L., Nanocrystals of Fe(Phen)2(NCS)2 and the SizeDependent Spin-Crossover Characteristics. Dalton Trans. 2015, 44, 17302-17311

34. Fishman, A. I.; Noskov, A. I.; Stolov, A. A., Conformational Mobility of Small Molecules in Glass-Forming Solutions Studied by Ftir Spectroscopy. Spectrochim. Acta A 2012, 91, 184.

35. Chelli, R.; Procacci, P.; Cardini, G.; Della Valle, R. G.; Califano, S., Glycerol Condensed Phases Part I. A Molecular Dynamics Study Phys. Chem. Chem. Phys. 1999, $1,871$.

36. Martin, J. P.; Zarembowitch, J.; Bousseksou, A.; Dworkin, A.; Haasnoot, J.; Varret, F., Solid State Effects on Spin Transitions: Magnetic, Calorimetric, and MoessbauerEffect Properties of $\left[\mathrm{Fe}_{\mathrm{x}} \mathrm{Co}_{1}-\mathrm{X}\left(4,4^{\prime} \text {-bis-1,2,4-Triazole }\right)_{2}(\mathrm{NCS})_{2}\right] \cdot \mathrm{H}_{2} \mathrm{O}$ Mixed-Crystal Compounds. Inorg. Chem. 1994, 33, 6325-6333. 
37. Rotaru, A.; Dirtu, M. M.; Enachescu, C.; Tanasa, R.; Linares, J.; Stancu, A.; Garcia, Y., Calorimetric Measurements of Diluted Spin Crossover Complexes [FexM 1 $\left.x(\text { btr })_{2}(\mathrm{NCS})_{2}\right] \mathrm{H}_{2} \mathrm{O}$ with $\mathrm{M}_{\mathrm{ii}}=\mathrm{Zn}$ and Ni. Polyhedron 2009, 28, 2351-2356.

38. Sorai, M.; Nakano, M.; Miyazaki, Y., Calorimetric Investigation of Phase Transitions Occurring in Molecule-Based Magnets. Chem. Rev. 2006, 106, 976-1031.

39. Castro, M.; Roubeau, O.; Pineiro-Lopez, L.; Real, J. A.; Rodriguez-Velamazan, J. A., Pulsed-Laser Switching in the Bistability Domain of a Cooperative Spin Crossover Compound: A Critical Study through Calorimetry. J. Phys. Chem. C 2015, 119, 1733417343.

40. Sorai, M.; Seki, S., Phonon Coupled Cooperative Low-Spin 1a1high-Spin 5t2 Transition in $\left[\mathrm{Fe}(\text { phen })_{2}(\mathrm{NCS})_{2}\right]$ and $\left[\mathrm{Fe}(\text { phen })_{2}(\mathrm{NCSe})_{2}\right]$ Crystals. J. Phys. Chem. Solids $1974,35,555$.

41. Zheng, W.; Simon, S. L., Confinement Effects on the Glass Transition of Hydrogen Bonded Liquids. J. Chem. Phys. 2007, 127. 
42. Roux, C.; Zarembowitch, J.; Itie, J. P.; Polian, A.; Verdaguer, M., Pressure-Induced Spin-State Crossovers in Six-Coordinate $F e(I I) L(N) L^{\prime}(M)(N C S)_{(2)}$ Complexes with $L=L^{\prime}$ and L Not Equal L': A XANES Investigation. Inorg Chem 1996, 35, 574-580.

43. Riggleman, R. A.; de Pablo, J. J., Antiplasticization and Local Elastic Constants in Trehalose and Glycerol Mixtures. Journal of Chemical Physics 2008, 128, 224504.

44. Ediger, M. D.; Angell, C. A.; Nagel, S. R., Supercooled Liquids and Glasses. J. Phys. Chem. 1996, 100, 13200-13212.

45. Willart, J. F.; Dudognon, E.; Mahieu, A.; Eddleston, M.; Jones, W.; Descamps, M., The Role of Cracks in the Crystal Nucleation Process of Amorphous Griseofulvin. Eur. Phys. J.-Special Topics 2017, 226, 837-847.

46. Mayergoyz, D., Mathematical Models of Hysteresis; Springer, New York, 1991.

47. Stancu, A.; Pike, C. R.; Stoleriu, L.; Postolache, P.; Cimpoesu, D., Micromagnetic and Preisach Analysis of the First Order Reversal Curves (FORC) Diagram. J. Appl. Phys.

2003, 93, 6620-6622. 
48. Nguyen, L. L.; Guillot, R.; Laisney, J.; Rechignat, L.; Bedoui, S.; Molnar, G.;

Rivière, E.; Boillot, M. L., Fe( $\left(\mathrm{Me}_{2} \text {-bpy }\right)_{2}(\mathrm{NCSe})_{2}$ Spin-Crossover Micro- and Nanoparticles

Showing Spin-State Switching above 250 K New. J. Chem. 2015, 39, 1603-1610.

49. Stoleriu, L.; Enachescu, C., Elastic Model for Spin Crossover Nanoparticles in Matrices Proc. Ro. Acad. Series A 2019, 20, 59-66.

50. Yokogawa, K.; Murata, K.; Yoshino, H.; Aoyama, S., Solidification of HighPressure Medium Daphne 7373. Jpn J. Appl. Phys. 2007, 46, 3636-3639.

51. Abou Hamad, I.; Robb, D. T.; Rikvold, P. A., New Cyclic Voltammetry Method for Examining Phase Transitions: Simulated Results. Journal of Electroanalytical Chemistry 2007, 607, 61-68.

52. Chen, M. Y.; Chen, X. R.; Ning, W. H.; Ren, X. M., A Facile Route for Preparation of Monodisperse Nanoparticles of One-Dimensional Fe(II)-4-Amino-1,2,4-Triazole Coordination Polymers with Hysteretic Spin-Crossover near Room Temperature. RSC Advances 2014, 4, 39126-39131. 
53. Bartual-Murgui, C.; Natividad, E.; Roubeau, O., Critical Assessment of the Nature and Properties of Fe(II) Triazole-Based Spin-Crossover Nanoparticles. J. Mater. Chem. C 2015, 3, 7916-7924.

54. Voisin, H.; Aimé, C.; Vallée, A.; Bleuzen, A.; Schmutz, M.; Mosser, G.; Corradin, T.; Roux, C., Preserving the Spin Transition Properties of Iron-Triazole Coordination Polymers within Silica-Based Nanocomposites. J. Mater. Chem. C2017, 5, 11542-11550.

55. Durand, P., et al., Room Temperature Bistability with Wide Thermal Hysteresis in a Spin Crossover Silica Nanocomposite. J. Mater. Chem. C 2013, 1, 1933-1942.

56. Herrera, J. M., et al., Studies on Bifunctional Fe(II)-Triazole Spin Crossover Nanoparticles: Time-Dependent Luminescence, Surface Grafting and the Effect of a Silica Shell and Hydrostatic Pressure on the Magnetic Properties. J. Mater. Chem. C $2015,3,7819-7829$. 


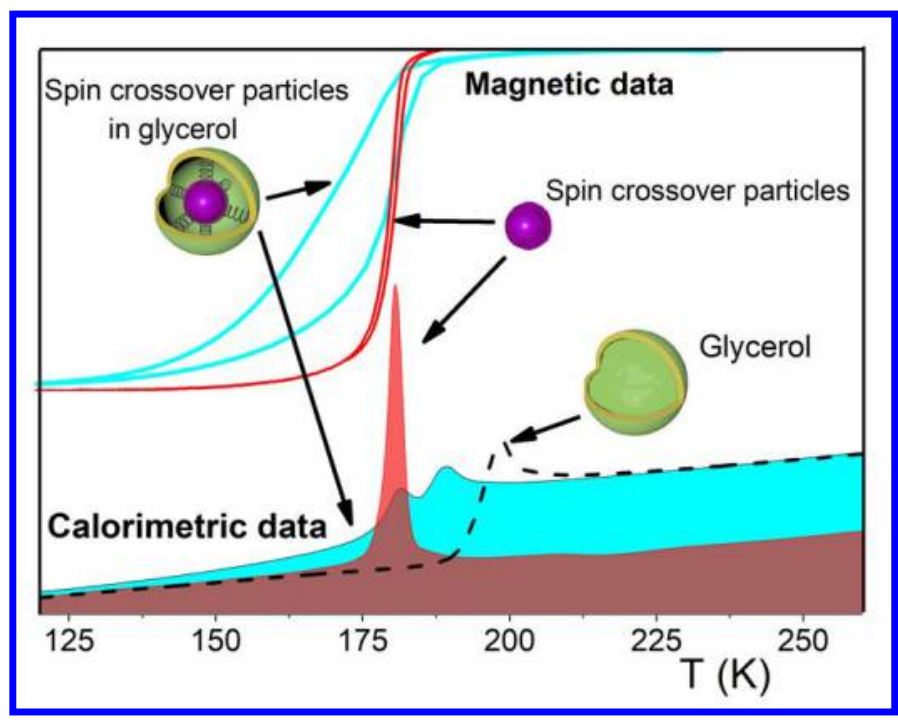

TOC graphic 


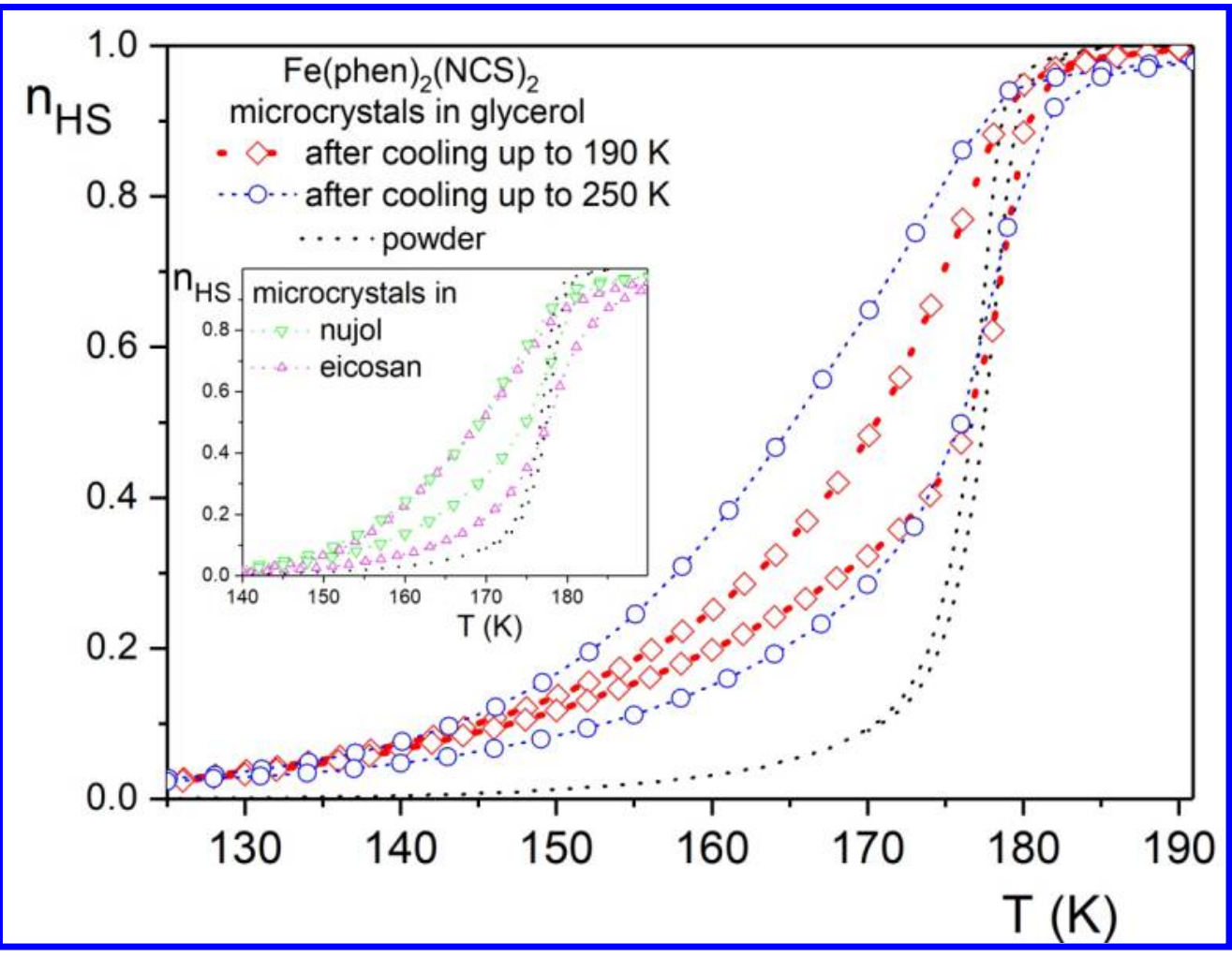

Major hysteresis loop (MHL) for Fe(phen)2(NCS)2 as polycrystalline powder (dotted line) and as dispersions of crystalline microparticles in glycerol after a first cooling down and heating up to 190 or $250 \mathrm{~K}$ (main figure) and as dispersions of crystalline microparticles in nujol and eicosan after a first cooling down and heating up to $190 \mathrm{~K}$ (inset). 


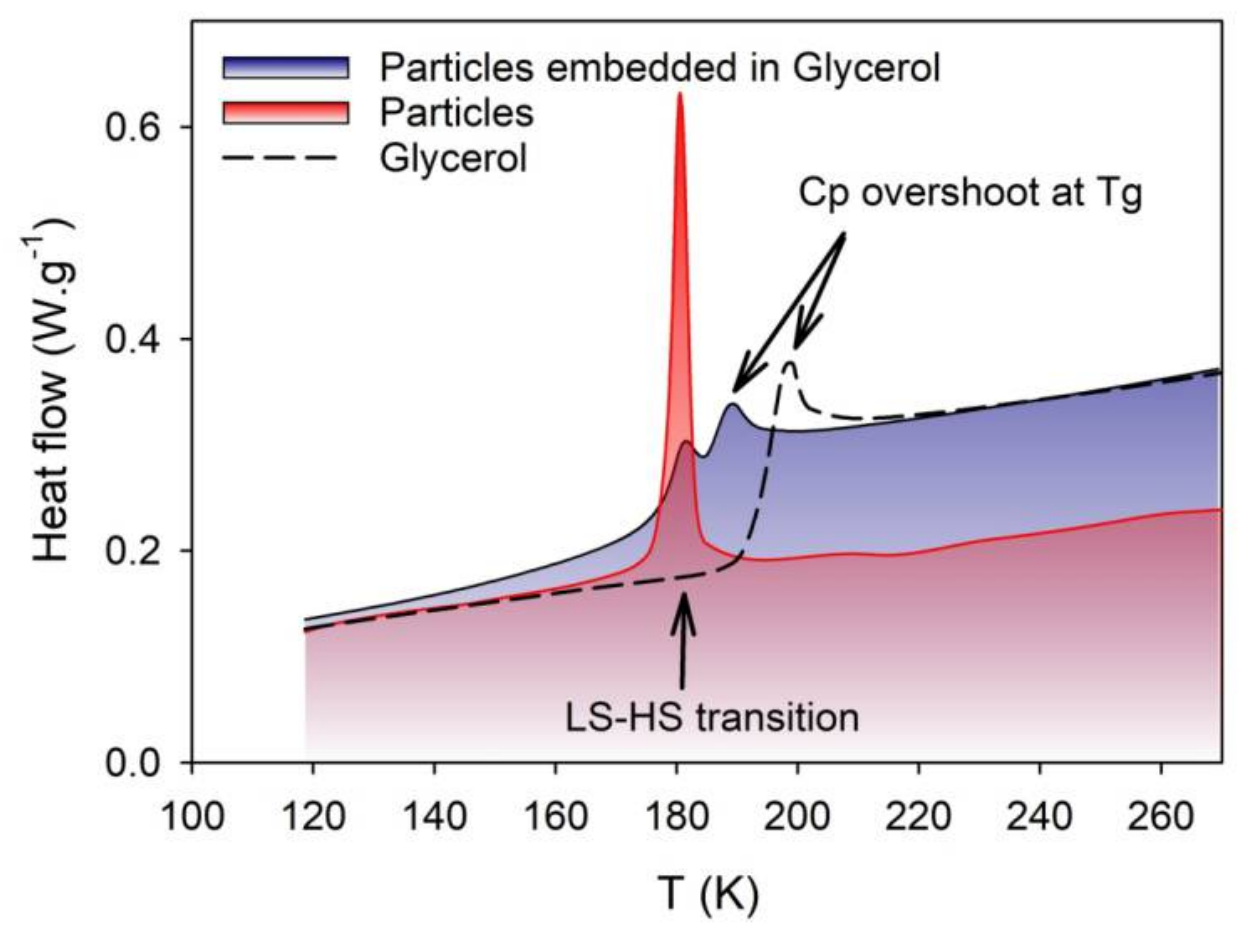

DSC thermograms recorded on heating after a first cooling down from 273 to $110 \mathrm{~K}$, with a temperature scanning rate of $10 \mathrm{~K} \cdot \mathrm{min}-1$ for pure glycerol (dashed line), free Fe(phen)2(NCS)2 microparticles (blue shaded) and Fe(phen)2(NCS)2 microparticles embedded in glycerol (red line).

$157 \times 119 \mathrm{~mm}(300 \times 300 \mathrm{DPI})$ 
Schematic representation of glycerol stable and metastable phases. The thermal treatments are shown by arrows: (a) cycling in the glassy and liquid phases in the range 100-250 K, (b) cycling in glassy phase 100$190 \mathrm{~K}$, and (c) cycling in the crystal 100-190 K 
DSC thermograms of $\mathrm{Fe}$ (phen)2(NCS)2 microparticles embedded in glycerol recorded with a temperature scanning rate of $0.5 \mathrm{~K} \cdot \mathrm{min}-1$ and with different cycling conditions. The two lower curves correspond to the cooling branches: a first cooldown after having heated the system above $250 \mathrm{~K}$ (dashed line) and a subsequent cooldown after heating up to $190 \mathrm{~K}$ (solid line). The two upper curves correspond to the heating branches (superimposed solid lines).

$158 \times 123 \mathrm{~mm}(300 \times 300 \mathrm{DPI})$ 


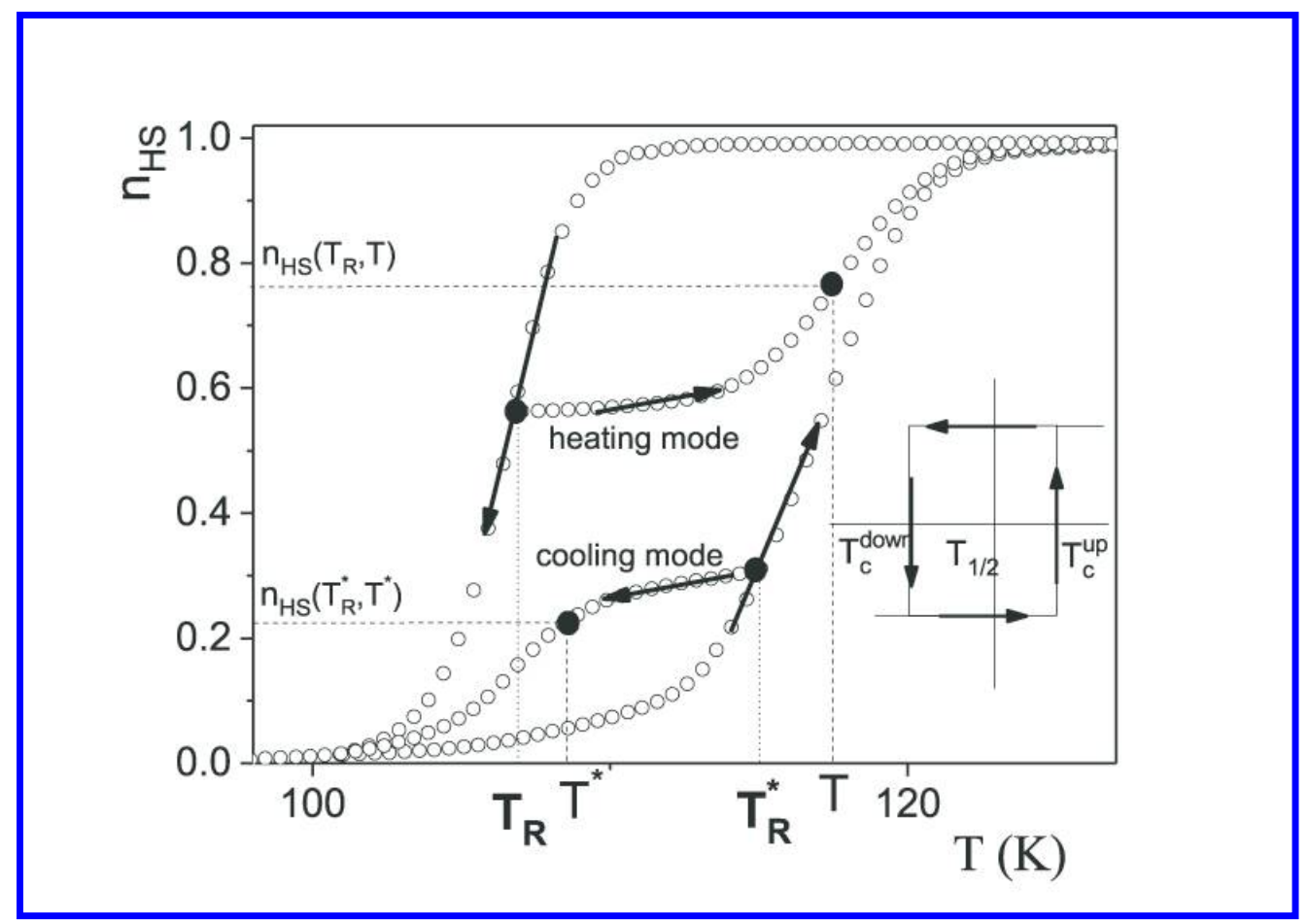

Examples of FORCs in warming and cooling modes; inset: typical hysteron for cooperative interactions 

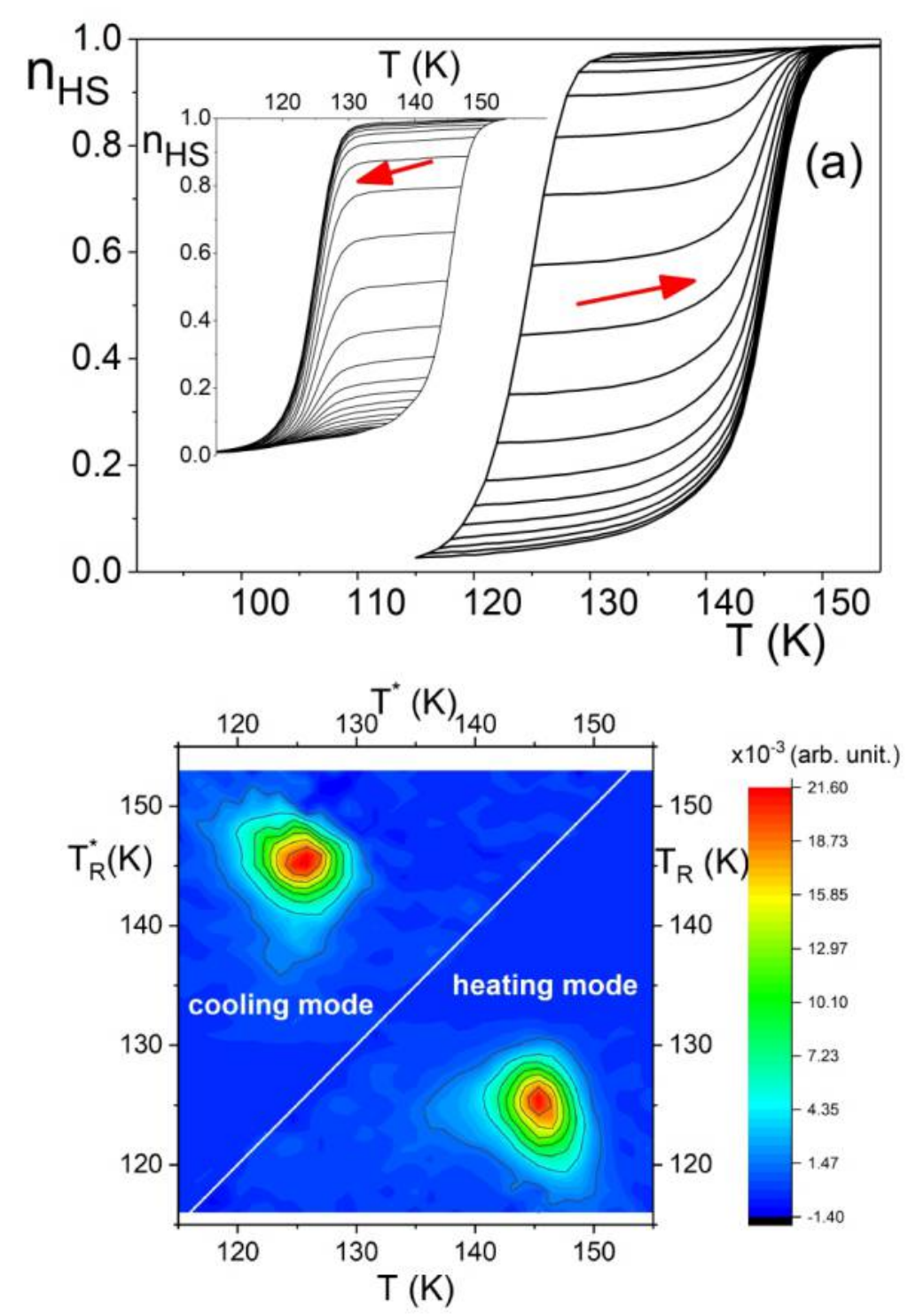

Figure 6 Typical FORCs in the case of powder spin-crossover compound [Fe(btr)2(NCS)2].H2O 5 (a) Main figure: heating mode, inset: cooling mode. (b) FORC distributions for heating (lower side) and cooling modes (upper side).

$359 \times 480 \mathrm{~mm}(300 \times 300 \mathrm{DPI})$ 

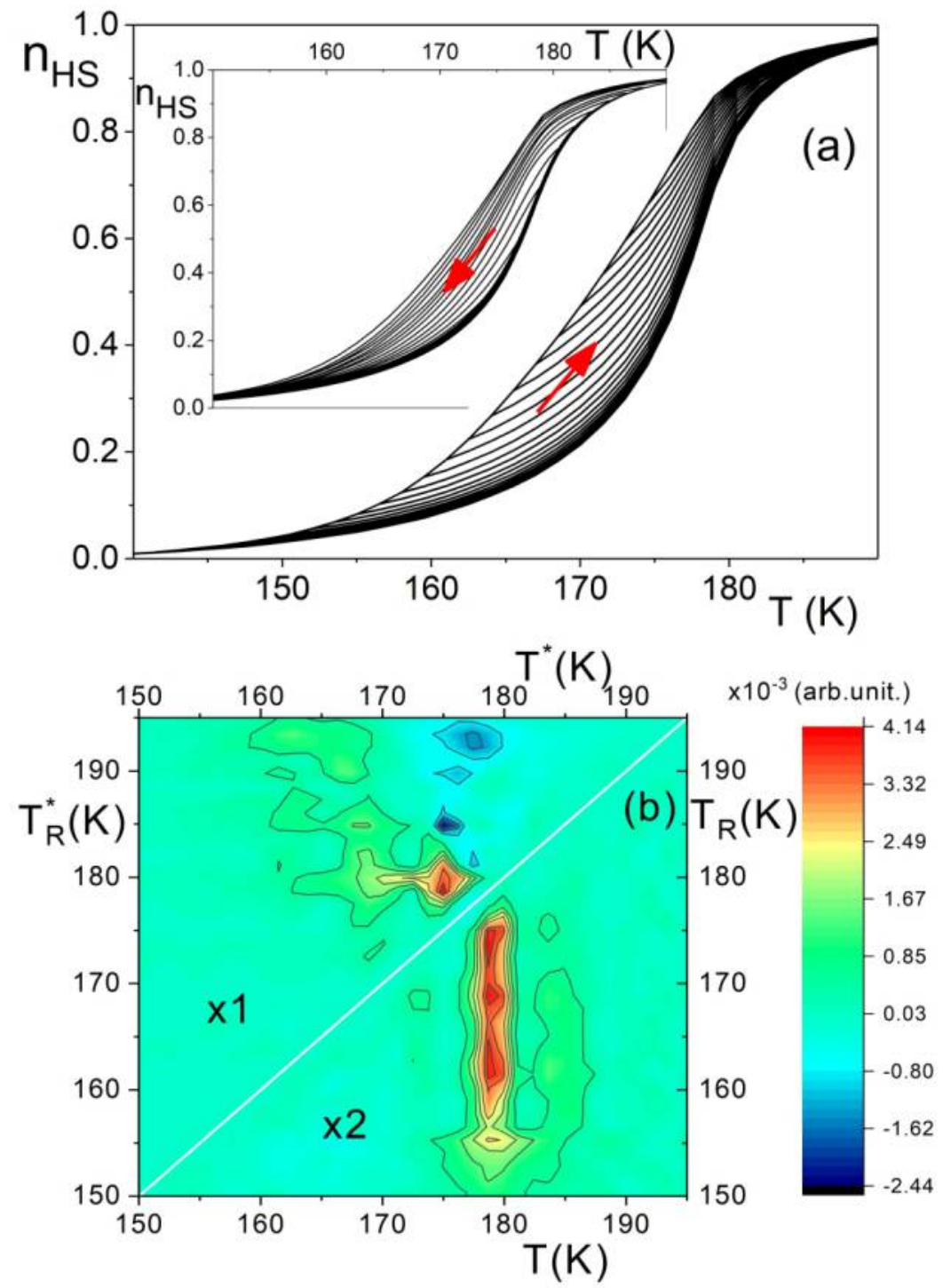

FORCs for Fe(phen)2(NCS)2 microparticles embedded in eicosan. (a) Main figure: heating mode (Tup = 190 $\mathrm{K}$ ), inset: cooling mode, Tdown $=140 \mathrm{~K}$ ). (b) FORC distributions for heating (lower side, multiplied by 2 ) and cooling modes (upper side). 


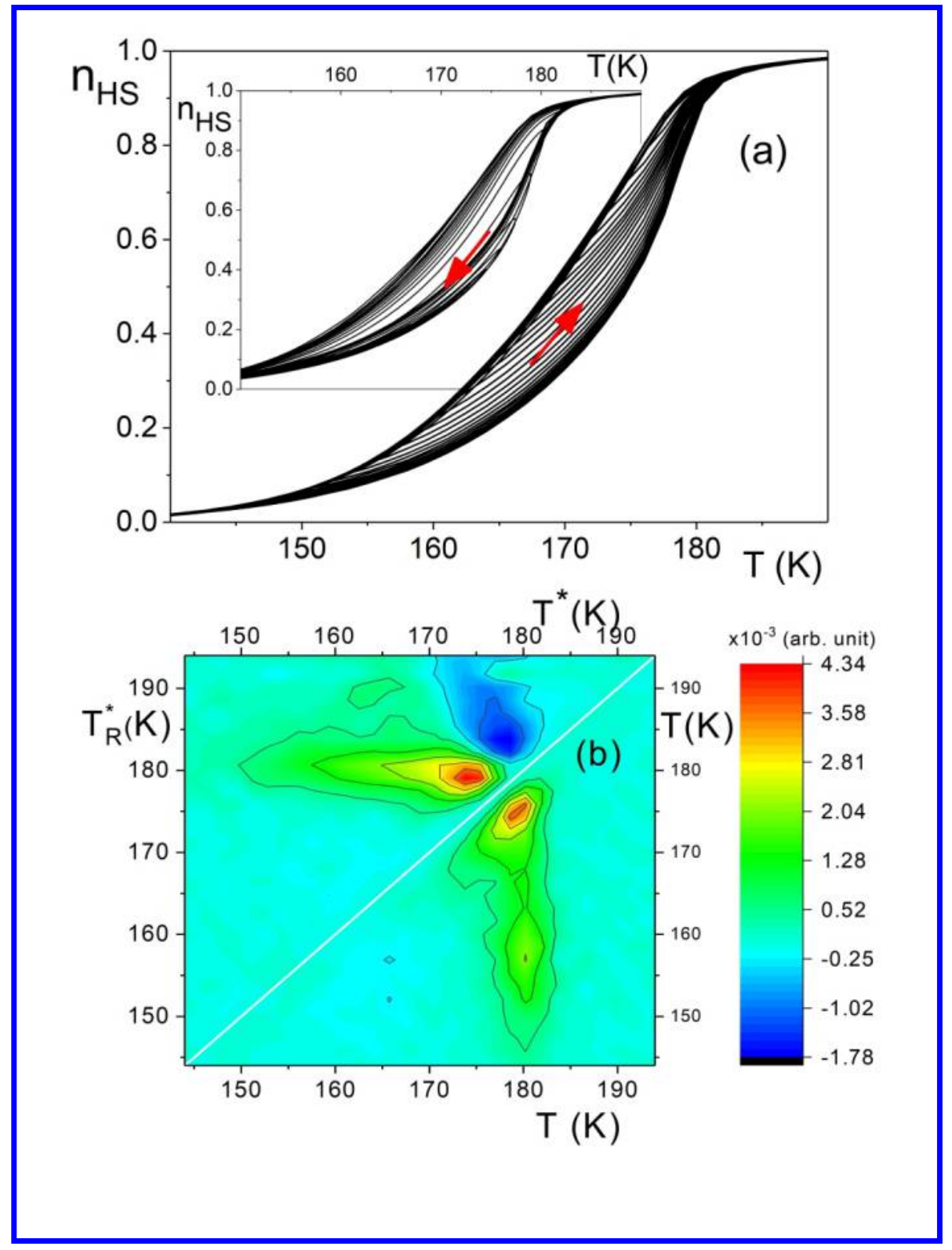

FORCs for Fe(phen)2(NCS)2 microparticles embedded in nujol. (a) Main figure: heating mode (Tup=190 K), inset: cooling mode (Tdown $=140 \mathrm{~K}$ ). (b) FORC distributions for heating (lower side) and cooling modes (upper side). 

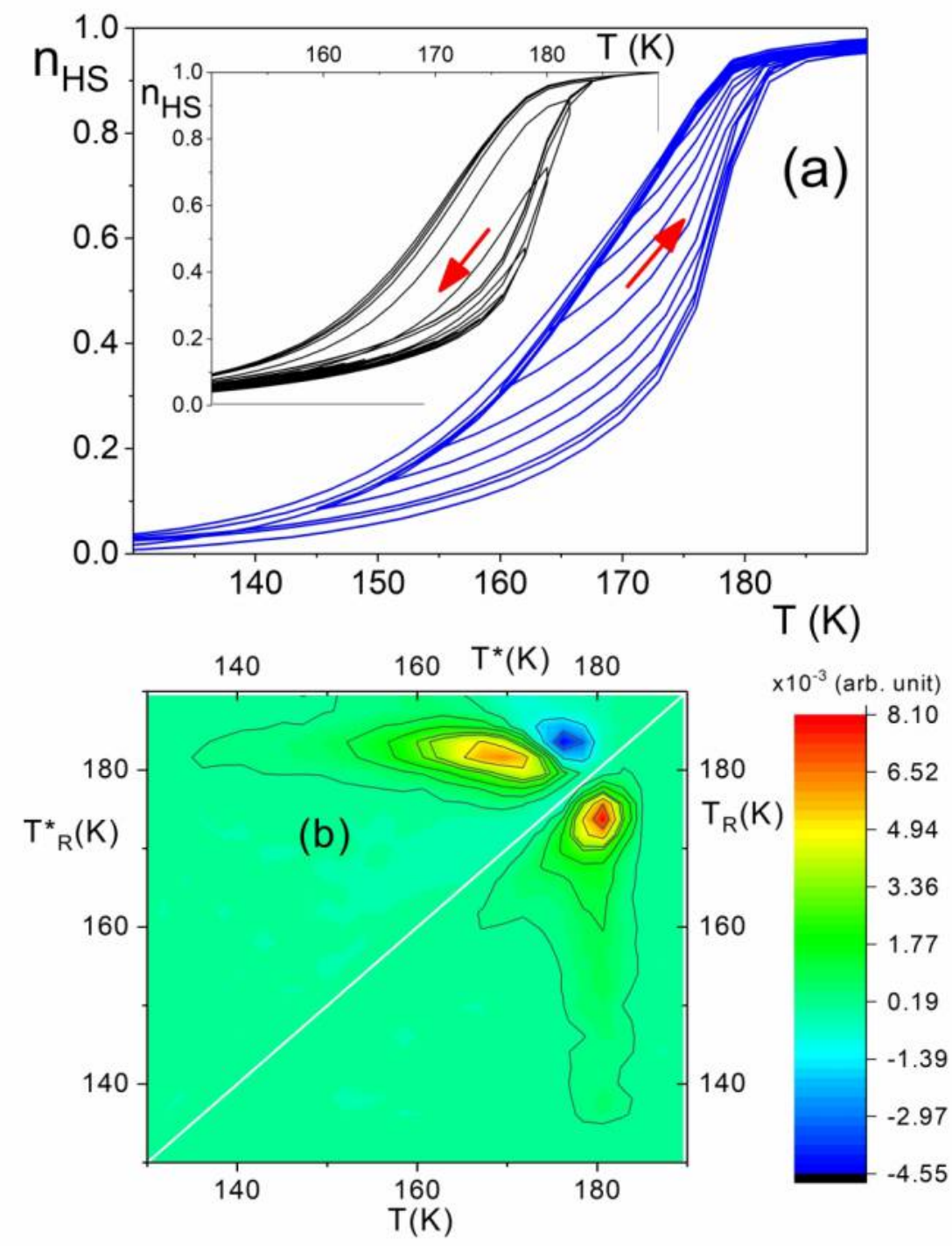

(a) FORCs for Fe(phen)2(NCS)2 microparticles embedded in glycerol for warming mode when cycling up to $250 \mathrm{~K}$, (main figure) and cooling modes (inset) (b) Corresponding FORC distributions. The temperature scan rate was $0.3 \mathrm{~K} \cdot \mathrm{min}-1$.

$359 \times 480 \mathrm{~mm}(300 \times 300$ DPI $)$ 

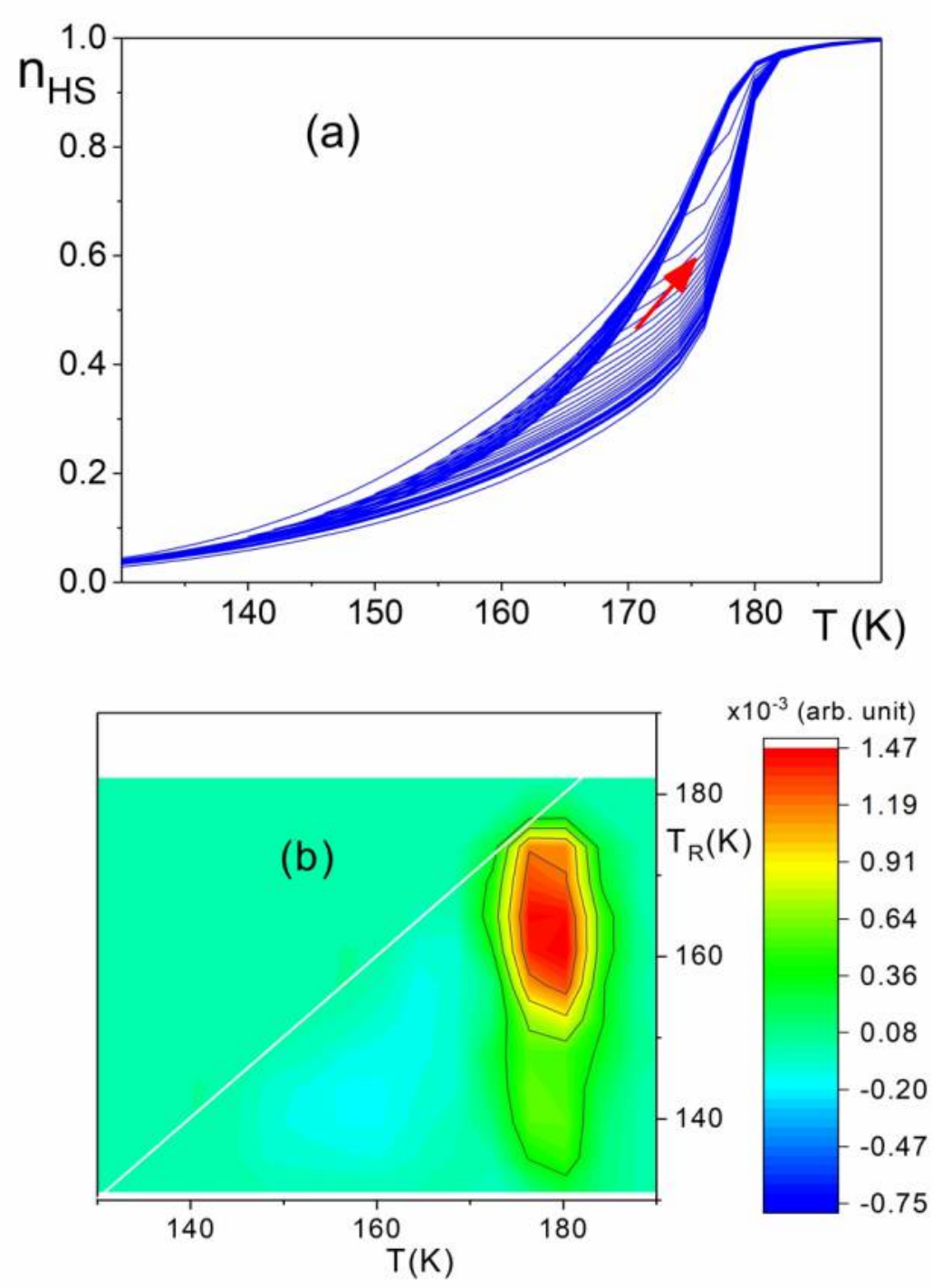

Figure 10 (a) FORCs for Fe(phen)2(NCS)2 microparticles embedded in glycerol for warming mode when cycling up to $190 \mathrm{~K}$ (main figure) (b) Corresponding FORC distributions. The temperature scan rate was 0.3 $\mathrm{K} \cdot \min -1$.

$359 \times 480 \mathrm{~mm}(300 \times 300$ DPI $)$ 


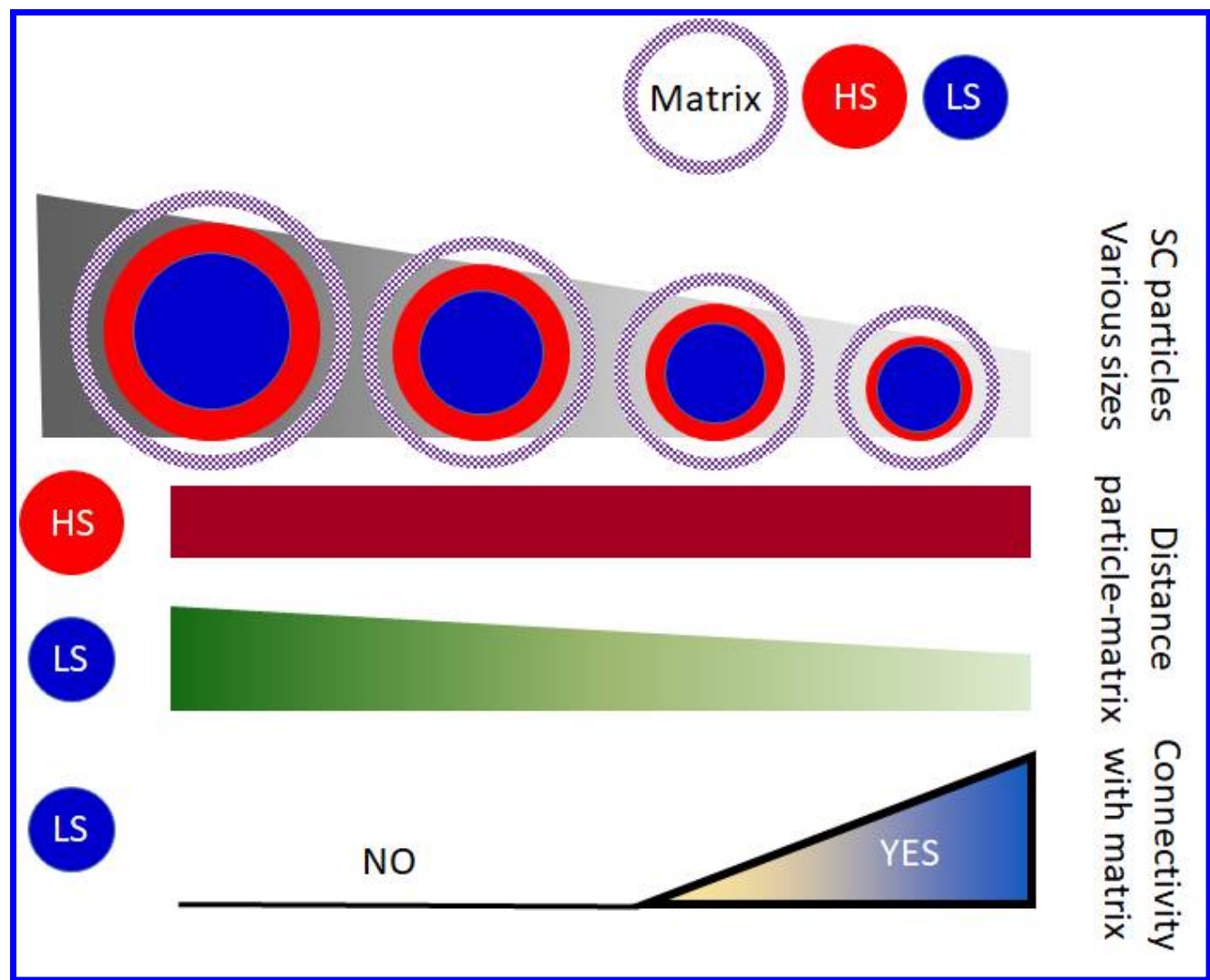

Schematic representation of particle-matrix interactions during HS-LS transition $243 \times 196 \mathrm{~mm}(72 \times 72 \mathrm{DPI})$ 


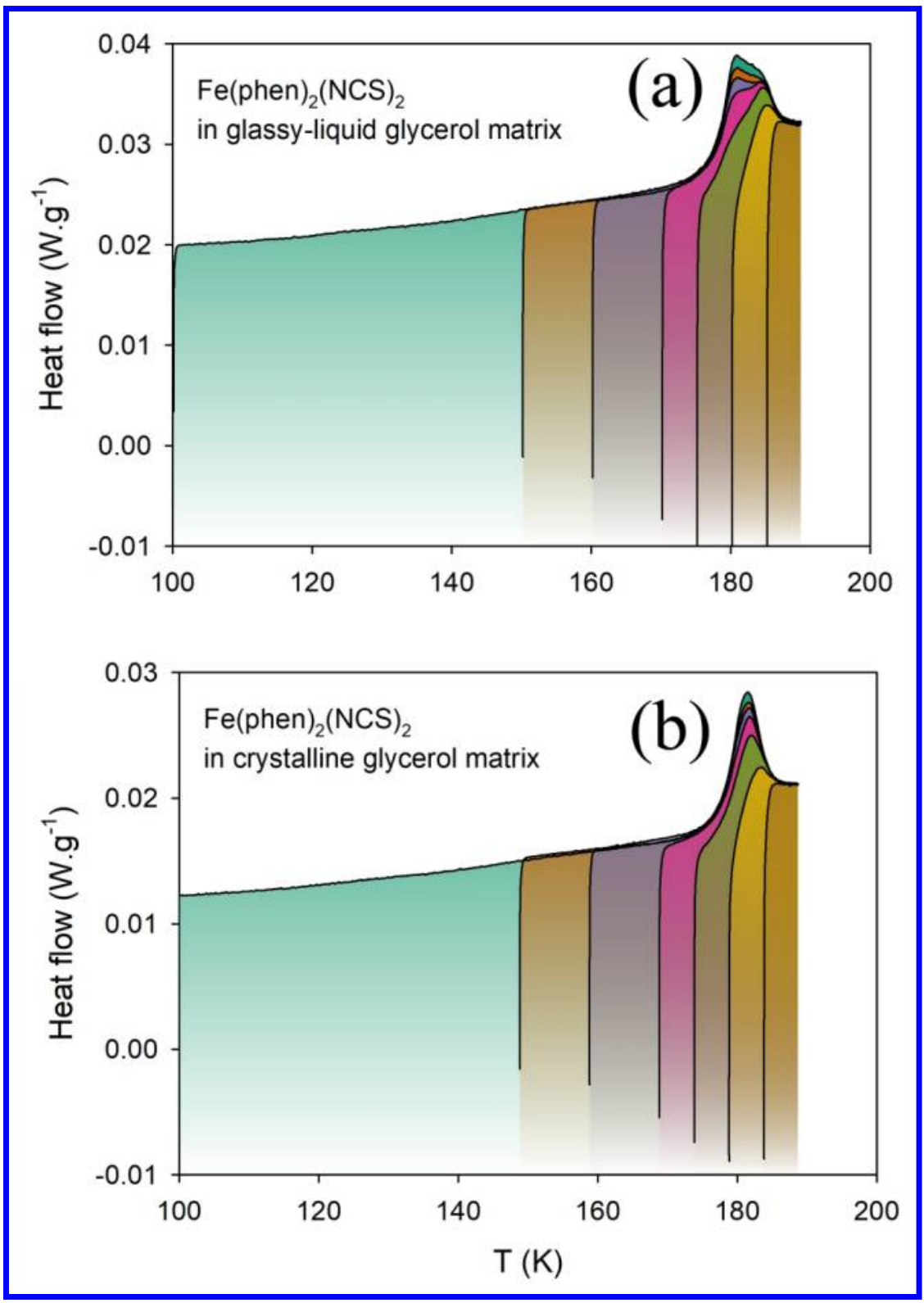

First Order Reversal Curves DSC thermograms in the heating mode for composites of Fe(phen)2(NCS)2 microparticles embedded in glassy (a) and crystalline (b) glycerol. 

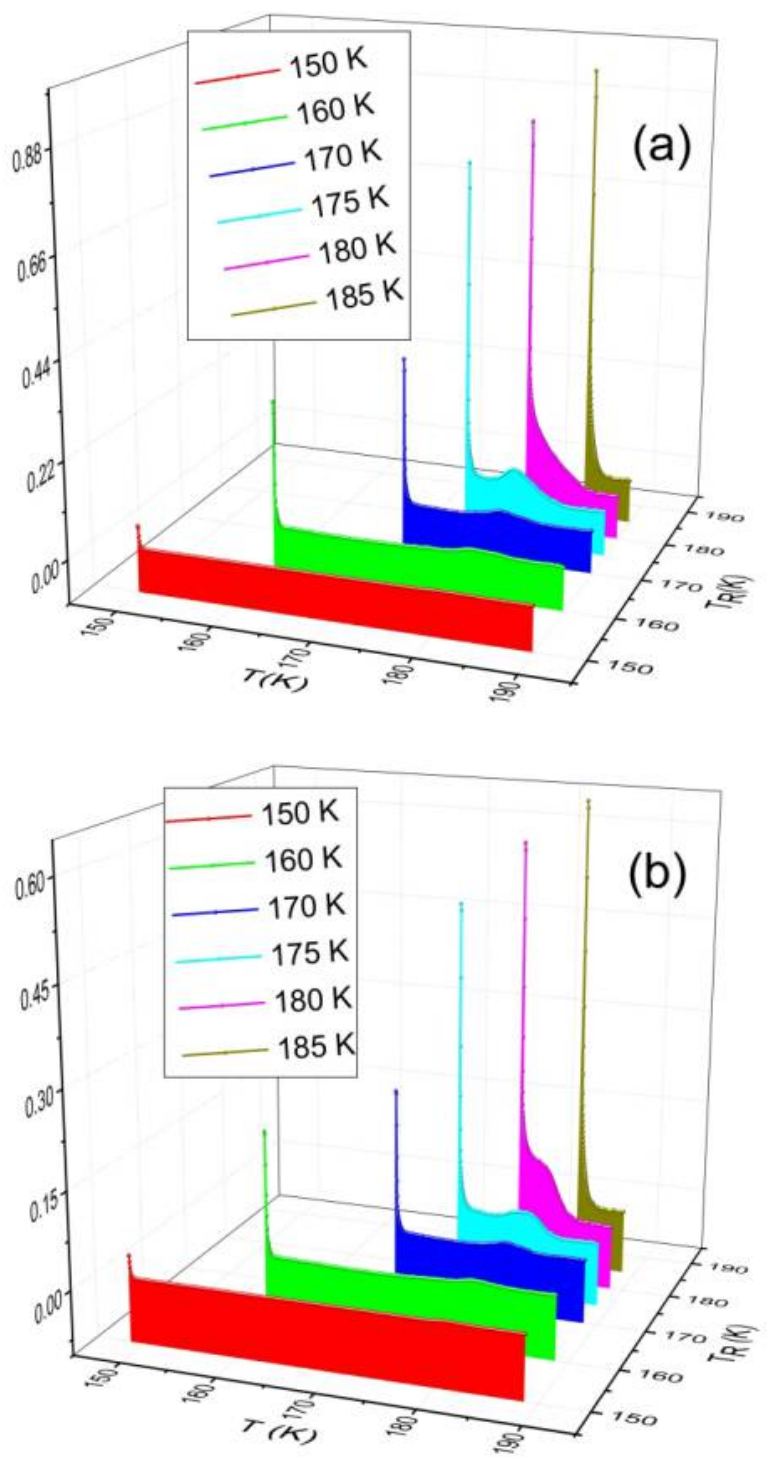

Calorimetric FORC distributions for compound embedded in glassy ( $a$, up) and crystalline matrices ( $b$, down). Note the reversible component (the high peaks) and the irreversible ones. 